\title{
Income distribution, credit and fiscal policies in an agent-based Keynesian model
}

\author{
Giovanni Dosi $^{\text {a,*, }}$ Giorgio Fagiolo ${ }^{\text {a,1 }}$, Mauro Napoletano ${ }^{\text {b,c,a,2, }}$ \\ Andrea Roventini d,a,b,3 \\ a Sant'Anna School of Advanced Studies, Piazza Martiri della Libertà 33, I-56127 Pisa, Italy \\ ${ }^{\mathrm{b}}$ OFCE, Bâtiment 2, 250 rue A. Einstein, 06560 Valbonne, France \\ c SKEMA Business School, 60 rue Dostoïevski, 06902 Sophia Antipolis Cedex, France \\ d Università di Verona, Dipartimento di Scienze Economiche, Via dell'Artigliere 19, I-37129 Verona, Italy
}

\section{A R T I C L E I N F O}

\section{Article history:}

Received 21 January 2012

Received in revised form

18 October 2012

Accepted 30 November 2012

Available online 13 February 2013

\section{JEL classifications:}

E32

E44

E51

E52

E62

Keywords:

Agent-based Keynesian models

Multiple equilibria

Fiscal and monetary policies

Income distribution

Transmission mechanisms

Credit constraints

\begin{abstract}
A B S T R A C T
This work studies the relations between income distribution and monetary/fiscal policies using an credit-augmented version of the agent-based Keynesian model in Dosi et al. (2010). We model a banking sector and a monetary authority setting interest rates and credit lending conditions in a framework combining Keynesian mechanisms of demand generation, a Schumpeterian innovation-fueled process of growth and Minskian credit dynamics. We show that the model is able to account for a rich ensemble of empirical features underlying current and past recessions, including the impact of financial factors on the real economy, and the role in that of income distribution. We find that more unequal economies are exposed to more severe business cycles fluctuations, higher unemployment rates, and higher probability of crises. From a policy perspective, the model suggests that fiscal policies dampen business cycles, reduce unemployment and the likelihood of experiencing a huge crisis and, in some circumstances, also affect longterm growth. Furthermore, the more income distribution is skewed toward profits, the greater the effects of fiscal policies. Interest rates have instead a strong non-linear effect on macroeconomic dynamics. Tuning the interest rate when it is below a given threshold has no detectable effects. Conversely, increasing the interest rate when it is above that threshold yields lower and more volatile output growth, higher unemployment rates, and higher likelihood of crises.
\end{abstract}

(c) 2013 Elsevier B.V. All rights reserved.

\section{Introduction}

This work studies the interactions between income distribution and monetary and fiscal policies in terms of ensuing dynamics of macro variables (GDP growth, unemployment, etc.) on the grounds of an agent-based Keynesian model. ${ }^{4}$

\footnotetext{
* Corresponding author. Tel.: +39050 883343; fax: +39050 883344 .

E-mail addresses: gdosi@sssup.it (G. Dosi), giorgio.fagiolo@sssup.it (G. Fagiolo), mauro.napoletano@ofce.sciences-po.fr (M. Napoletano), andrea.roventini@univr.it (A. Roventini).

${ }^{1}$ Tel.: + 39050 883359; fax: + 39050883344 .

${ }^{2}$ Tel.: + $33(0) 489737106$.

${ }^{3}$ Tel.: + 390458028238 ; fax: + 390458028529

${ }^{4}$ In this work we employ the term "income distribution" meaning functional distribution (i.e. how income is distributed between wages and profits), as distinct from personal income distribution (related to how income is distributed across individual agents in the population). However, empirically the two move in the same direction. Hence, in the model below an unequal "functional" income distribution should be considered also as a proxy for an unequal "individual" income distribution.
} 
The empirical counterpart of this work is quite straightforward. Major recessions characterized by negative growth and prolonged periods of high unemployment rates are recurrent phenomena in the history of capitalist economies, and so are persistent fluctuations in output and employment. In all that, financial factors often appear to play an important role, at least as triggering factors of the outburst of recessionary dynamics: it was so in the Great Depression of 1929 , and similarly is with the subprime mortgage crisis in the current Great Recession. Conversely, on the real side, income distribution is a serious candidate in the determination of degrees of (negative or positive) amplification of demand impulses. Interestingly, when one looks at how income is cross-sectionally distributed among individuals, one finds that contemporary industrialized economies have never been so unequal since the Great Depression. So, for example, in the U.S. the ratio between the top $1 \%$ and the bottom $90 \%$ of incomes has gone from less than 2.6 in the 1970 s to more than 3.7 in the new millenium (Atkinson and Piketty, 2010). Indeed, there are solid reasons to believe that individual-income inequality is contributing - now as well as in the aftermath of the 1929s crisis - to depress aggregate demand (Fitoussi and Saraceno, 2010; Kumhof and Rancière, 2010; Stiglitz, 2011). In the model that follows we shall precisely explore the relationships between financial and real domains of the economy, the role played by income distribution (proxied by the distribution of income between profits and wages) and the impact of monetary and fiscal policies in shaping macrodynamics.

The direct ancestor of this work is the "Keynes meeting Schumpeter" formalism ( $+\mathrm{S}$, henceforth) presented in Dosi et al. (2010). To that model, we add a banking sector and a monetary authority setting interest rates and credit lending conditions.

Our approach considers the economy as a complex evolving system, i.e. as an ecology of heterogenous agents whose farfrom-equilibrium interactions continuously change the structure of the system itself (more on that in Kirman, 2010; Dosi, 2011; Rosser, 2011). In this framework, the statistical relationships exhibited by macroeconomic variables should be considered as emergent properties stemming from microeconomic disequilibrium interactions.

More specifically, we develop an agent-based model that combines Keynesian mechanisms of demand generation, a "Schumpeterian" innovation-fueled process of growth and Minskian credit dynamics.

The model, with its evolutionary roots (Nelson and Winter, 1982), belongs to the growing body of literature on agentbased models (Tesfatsion and Judd, 2006; LeBaron and Tesfatsion, 2008) addressing the properties of macroeconomic dynamics (more on that in Section 2 below). ${ }^{5}$ The model is grounded on a "realistic" - i.e. rooted in micro empirical evidence - representation of agents' behavior, thus providing an explicit "behavioral" microfoundation of macro dynamics (Akerlof, 2002). The robustness of the model is checked against its capability to jointly account for a large set of empirical regularities both at the micro level (e.g. firm size and growth-rate distributions, productivity dispersions, firm investment patterns) and at the macro one (e.g. persistent output growth, output volatility, unemployment rates, etc.).

The model portrays an economy composed of capital- and consumption-good firms, a population of workers, a bank, a Central Bank and a public sector. Capital-good firms perform R\&D and produce heterogeneous machine tools. Consumption-good firms invest in new machines and produce a homogeneous consumption good. Firms finance their production and investment choices employing internal funds as well as credit provided by the banking sector. The Central Bank fixes the interest rate and determines the credit multiplier. Finally, the public sector levies taxes on firm profits and worker wages, and pay unemployment benefits.

As in every ABM, the properties of the model are analyzed via extensive computer simulations. We perform our simulations exercises employing a three-steps strategy. First, we empirically validate the model, i.e. we assess whether the statistical properties of simulated microeconomic and macroeconomic data are similar to empirically observed ones. Second, we experiment with different income distribution scenarios and study a few key implications in terms of macrodynamics. Third, we use the model as a sort of "policy laboratory" exploring the short- and long-run effects of different fiscal and monetary policies.

In line with Dosi et al. (2010), the model is able to match a long list of macro and micro empirical regularities. Moreover, the extended version of the $\mathrm{K}+\mathrm{S}$ model can replicate new macro and micro stylized facts concerning credit dynamics (including procyclical firm debt and bankruptcy rates, power-law distributed firm-level "bad debt", etc.).

We believe that the credit-enhanced $\mathrm{K}+\mathrm{S}$ model is able to catch salient features underlying the current as well as previous recessions, the impact of financial factors and the role in them of income distribution. Indeed, we find that different income distribution regimes heavily affect macroeconomic performance: more unequal economies (i.e. economies where income distribution is more skewed towards profits) are exposed to more severe business cycles fluctuations, higher unemployment rates, and higher probability of crises.

Moreover, the interactions between credit dynamics and economic fluctuations are strongly "Minskian". The model can easily account for regimes whereby higher production and investment levels rise firms' debt, eroding their net worths and consequently increasing their credit risk. Banks, in turn, increase the level of credit rationing in the economy and force firms to curb production and investment, thus setting the premises for an incoming recession.

\footnotetext{
${ }^{5}$ For germane ABMs, see Verspagen (2002), Delli Gatti et al. (2005, 2010, 2011), Saviotti and Pyka (2008), Dawid et al. (2008, 2011), Ciarli et al. (2010), Ashraf et al. (2011), Cincotti et al. (2010), and Gai et al. (2011). See also Fagiolo and Roventini (2012) for a critical comparison of policy analysis in DSGE and agent-based models.
} 
On the policy side, the credit-augmented $\mathrm{K}+\mathrm{S}$ model can be usefully employed to assess the effects of fiscal and monetary policies under various income distribution scenarios. Simulation exercises reveal the strong interactions between income distribution on the one side, and fiscal and monetary policies on the other.

As in Dosi et al. (2010), fiscal policies do not only dampen business cycles, reduce unemployment and the likelihood of experiencing a huge crisis, but in some circumstances are able to also affect long-term growth. Here, we are able to generalize that result. The more income distribution is skewed toward profits, the greater the effects of fiscal policies. Conversely, on the monetary policy side, we find a strong non-linearity in the way interest rates affect macroeconomic dynamics. More specifically, there exists a threshold beyond which increasing the interest rate implies smaller output growth rates and larger output volatility, unemployment and likelihood of crises. Again, the impact of interest rate policies is affected by income distribution: changes in interest rates have a milder impact on more "unequal" economies, because higher profit rates allow firms to be relatively more independent from bank credit. Similarly, the sensitivity of real variables to policies affecting credit multipliers falls with higher profit margins.

The rest of the paper is organized as follows: in Section 2 we outline some of the theoretical roots of our work. In Section 3 we introduce a credit augmented version of the $\mathrm{K}+\mathrm{S}$ model. Simulation results are presented in Section 4 , and Section 5 concludes.

\section{Some theoretical roots}

As mentioned, one major root of the model is evolutionary and Schumpeterian: the growth process is fueled by decentralized uncertainty-ridden activities of innovation and imitation. And the second major root is Keynesian: the model generically allows for non-Say quasi-equilibria (we borrow the expression from Krugman, 2011) and growth paths characterized by distinct growth rates and by varying levels of unemployment.

On the grounds of those two major roots, a central focus of the work that follows regards the links between financial and real dynamics. Here the reference is the large literature that has investigated the role of credit in generating business cycles, and in the transmission of monetary-policy effects to the real economy. The idea that credit heavily affects real variables has had mixed fortunes in macroeconomics. Although both Keynes (1936) and Fisher (1933) emphasized the role that credit played in the triggering of the Great Depression, the importance of credit markets was diminished by a long tradition - within both Keynesian and Monetarist camps - that focused on the money market as the key transmission channel of monetary policies to the real economy. For instance, according to the textbook IS-LM model, monetary policy operates through the effects that changes in the quantity of outside money exert on the composition of agents' portfolios between money and bonds. In turn, such changes alter the nominal and (in the presence of price-stickiness) real interest rates, thereby changing the level of aggregate investment. Indeed, the foregoing "money view" of the transmission mechanisms of monetary policy dominated the scene for quite a long time. ${ }^{6}$ And of course, it is well complemented by micro claims on the irrelevance of the firm financial structure for real investment decisions (cf. the (in)famous Modigliani and Miller, 1958, theorem).

In contrast with the above, Gurley and Shaw (1955) long ago proposed a "lending view" approach to the analysis of the transmission mechanisms of monetary policies. ${ }^{7}$ In this perspective, it is the level and composition of lending activities (and not the quantity of money) that is central in the transmission to the real economy. Such a view is well in tune with Kindleberger (1978) and Minsky (1975, 1982, 1986), who proposed explanations of crises where (i) credit and money are imperfect substitutes; (ii) firms' financial structures affect the determination of their investment and production choices; and (iii) prices do not only allocate resources between alternative uses, but also determine the profits of the firms, and, through this, their survival, growth or bankruptcy. In particular, Minsky $(1977,1986)$ formulated a theory of endogenous business cycles wherein the dynamics of credit and of financial fragility played major roles. According to this view, every investment burst contains in itself the seeds for the next phase of recession and crisis. An improvement in the financial robustness of firms, - e.g. due to an increase in the stock of their liquid assets or to a reduction in the interests paid on debt - foster production and investment. The financing of this expansion, however, erodes the internal funds of the firm and shifts its financial structure towards more external financing. This in turn increases its financial fragility and thereby the lender's and borrower's risk in credit contracts. If lenders respond by tightening credit standards, firms are forced to reduce production and investment.

In the nineties, a good deal of theoretical works has tried to formalize some of the foregoing insights and to squeeze them to different degrees into an orthodox framework.

A first stream of works on the so called "financial accelerator" literature (see e.g. Bernanke et al., 1999; Kiyotaki and Moore, 1997) attempts to microfound some of the intuitions of Minsky's and Gurley and Shaw's analyses (non-neutrality of firms' financial structure, role of borrower and lender's risk) plugging asymmetric information into an otherwise Real Business Cycle framework. ${ }^{8}$ A second stream (cf. Greenwald and Stiglitz, 1993; Bernanke and Blinder, 1988, among others) does the same without the RBC scaffolding.

\footnotetext{
${ }^{6}$ Incidentally note that this is also the basic transmission mechanism allowed by DSGE models with sticky prices (see e.g. Woodford, 2003; Christiano et al., 2005; Smets and Wouters, 2007).

${ }^{7}$ Hubbard (1995) and Gertler (1988) compare the money vs. the lending view of the monetary transmission mechanisms. See also Mishkin (1995) for a discussion of the different transmission mechanisms proposed in the macroeconomic literature.

${ }^{8} \mathrm{~A}$ follow up to this type of models is represented by the recent works trying to include financial accelerator mechanisms and financial intermediaries into a DSGE-type framework, see e.g. Gertler and Kiyotaki (2010).
} 
Indeed, a common property of asymmetric information between shareholders and managers, or between lenders and borrowers, is that it generally leads to phenomena such as equity or credit rationing (Stiglitz and Weiss, 1992). In such instances, small shocks to firms' net worth can have large aggregate consequences on real variables by changing firm bankruptcy risk or the value of collateral provided in credit contracts.

There are two main channels through which monetary policy effects are transmitted to the real economy through the credit market (see e.g. Hubbard, 1995). The first channel operates via the effects that monetary policy actions exerts on the balance sheets of borrowers ("balance sheet channel"). An increase in the interest rate raises borrowers' debt burden and reduces the level of net worth, with (i) rising the cost of external finance; (ii) lower availability of internal funds for production and investment; and (iii) decreasing collaterals that can be offered to lenders in credit contracts. The overall result is a reduction in investment and production expenditures. The other channel, is represented by the effects of monetary policy on the ability of bank to lend ("bank lending channel"). When banks are subject to reserve requirements, a monetary contraction drains reserves and can lead to a reduction in banks' ability to lend (see e.g. Bernanke and Blinder, 1988). As a result, credit allocated to bank-dependent borrowers may decrease, leading to a curtailed spending by the latter (see Bernanke and Blinder, 1988).

Both the balance sheet and bank lending channels have received empirical support from time-series studies (e.g. Bernanke and Blinder, 1992; Kashyap et al., 1993; Lown and Morgan, 2006; Claessens et al., 2009) as well as from crosssectional ones (e.g. Fazzari et al., 1988; Gertler and Gilchrist, 1994; Kashyap and Stein, 2000; Leary, 2009), including studies encompassing the last recession (Black and Rosen, 2011; Ciccarelli et al., 2010).

Financial accelerator models constitute an important advance in the understanding of the role of credit in the generation of business cycle fluctuations. At the same time, the major limit of many of them is that they are nested into a representation of the real side of the economy (the RBC or, more recently, the DSGE framework) with the full neglect of aggregate demand issues, the censorship of any heterogeneity across agents, and no possibility of endogenous credit cycles. On the contrary, in the model that follows, we shall fully take on board the two channels of "financial acceleration" avoiding such major drawbacks.

In contrast to financial accelerator models, aggregate demand plays a key role in the strand of literature on credit and business cycles nearer to the structuralist and post-Keynesian traditions (cf. Taylor and O'Connell, 1985; Chiarella et al., 2001; Palley, 1994; Keen, 1995; Fazzari et al., 2008; Patriarca and Vona, in this issue; Charpe et al., 2009, among others). Models developed in this framework are able to generate endogenous cycles with Minskian features. In particular, Palley (1994), Keen (1995), and Charpe et al. (2009) study the interactions between debt and income distribution in a Goodwintype model of business cycles, bearing in that respect a good deal of similarity with our model. On the other hand, they all structure their models as systems of macro-dynamics equations describing the interaction between the financial and the real part of the economy. Conversely, in the model below and in tune with the macro agent-based literature (Delli Gatti et al., 2005; Russo et al., 2007; Cincotti et al., 2010; Ashraf et al., 2011; Chiarella and Di Guilmi, 2011; Raberto et al., 2012), finance-real interactions and the possible ensuing fluctuations are nested over an ecology of multiple heterogeneous agents. In this respect, our model is rather close to the financial fragility model of Delli Gatti et al. (2005), in turn building on the insights of Greenwald and Stiglitz (1993). Unlike that model, however, we ground our financial-real dynamics on a "Keynes plus Schumpeter" root, with endogenous technical change (in analogy with Russo et al., 2007; Delli Gatti et al., 2011) and also (partly) endogenous generation of aggregate effective demand.

\section{The credit-augmented $\mathrm{K}+\mathrm{S}$ model}

Let us present the main features of the model, an extended version of Dosi et al. (2010), to which we refer for more details. The model portrays an economy composed of a machine-producing sector made of $F_{1}$ firms (denoted by the subscript $i$ ), a consumption-good sector made of $F_{2}$ firms (denoted by the subscript $j$ ), $L^{S}$ consumers/workers, a bank, a Central Bank and a public sector. Capital-good firms invest in R\&D and produce heterogeneous machines. Consumption-good firms combine machine tools bought by capital-good firms and labor in order to produce a final product for consumers. Firms deposit in the bank their cash flows. The bank provides credit to firms. Credit is allotted to firms on a pecking-order basis according to their stock of liquid assets. The Central Bank affects the supply of loans and the actual dynamics of debt of the firms in the economy fixing the interest rate and the credit multiplier. Finally, the public sector levies taxes on firms' profits and pays unemployment benefits.

In what follows, we will briefly describe the bank-augmented $\mathrm{K}+\mathrm{S}$ model paying particularly attention to the dynamics of the credit market (cf. Section 3.4). A full description of the real side of the economy is in Appendix A.

\subsection{The timeline of events}

In any given time period $(t)$, the following microeconomic decisions take place in sequential order:

1. Policy variables are fixed (e.g. a Central Bank setting the interest rate at which it lends to the bank and the reserve requirement of the latter; the "Government" setting tax rates and unemployment benefits, etc.).

2. Machine-tool firms perform R\&D trying to discover new products and more efficient production techniques and to imitate the production technology and the products of their competitors. Capital-good firms advertise their machines to consumption-good firms. 
3. Consumption-good firms decide how much to produce and invest. If investment is positive, consumption-good firms choose their supplier, send their orders and pay for the machines. When internal funds are not enough to finance production and investment plans, firms borrow (up to a ceiling) from the bank.

4. Total credit provided by the bank to each firm is determined.

5. In both industries firms hire workers according to their production plans if below their credit ceiling or at the ceiling otherwise and start producing.

6. Imperfectly competitive consumption-good market opens. The market shares of firms evolve according to their price competitiveness.

7. Firms in both sectors compute their net cash flow, pay back their due loans to the bank to the extent that they have cash flow to do that and deposit their savings, if any.

8. Entry and exit take place. In both sectors firms with near-zero market shares and/or negative net liquid assets ${ }^{9}$ are eschewed from their industry and replaced by new firms (for simplicity, we keep the number of firms fixed; any dead firm is replaced by a new one; and entrant firms are random copies of incumbent ones). ${ }^{10}$

9. Machines ordered at the beginning of the period are delivered and become part of the capital stock at time $t+1$.

At the end of each time step, aggregate variables (e.g. GDP, investment, employment) are computed, summing over the corresponding microeconomic quantities.

\subsection{The capital-good industry}

The technology of capital-good firms evolves along the vintages of produced machine tools. Each firm specific generation of machine tools has indeed a distinct production cost and distinct labour productivity for the user. Machine selling prices are set with a mark-up rule ${ }^{11}$ over production costs.

Innovation and imitation are costly processes: machine-producing firms invest in R\&D a fraction of their past revenues and hire researchers at the current market wage. Firms finance R\&D investment using internal funds. ${ }^{12}$

Both innovation and imitation follow a two-step stochastic process. In the first step, the resources allocated to search determine in probability whether the events "innovation" and "imitation" are drawn. Note that the newly discovered capital goods might be a "failed innovation", because production costs might be higher and/or user efficiency might be lower than the currently manufactured machines. Indeed, at the second stochastic stage, each firm draws the characteristics of the would-be machine and decide whether to keep on producing the current generation of machines or to switch to the new vintage, by evaluating the possible trade-off between production costs and productive efficiencies (of course, it could be also that the new machine is both cheaper and more efficient, or more expensive and less efficient). Once the machine tool is chosen, capital-good firms try to reach their customers under conditions of imperfect information: hence, we assume that they send a "brochure" with the price and the productivity of their machines to both their historical clients and a random sample of potential new customers.

Finally, profits of capital good firms are equal to:

$$
\Pi_{i}(t)=S_{i}(t)-c_{i}(t) Q_{i}(t)-R D_{i}(t),
$$

where $S_{i}(t), c_{i}(t) Q_{i}(t)$ and $R D_{i}(t)$ denote, respectively, sales, total labor costs, and R\&D expenditures of the capital-good firm $i$.

Machines are paid in advance in the model. Therefore, the equation for the dynamics of the stock of liquid assets of a capital-good firm is:

$$
N W_{i}(t)=N W_{i}(t-1)+\Pi_{i}(t) .
$$

\subsection{The consumption-good industry}

Consumption-good firms produce a homogenous good using capital (i.e. their stock of machines) and labor under constant returns to scale. Firms plan their production according to adaptive demand expectations. ${ }^{13}$ The desired level of

\footnotetext{
9 This assumption implies that bankruptcies in this model are due only to illiquidity problems as opposed to bankruptcy due to solvency problems (i.e. to a negative difference between the values of assets and liabilities). See Raberto et al. (2012) for an agent-based model featuring both types of bankruptcies.

10 The assumption about a constant number of firms in the market is justified by the large cross-country and cross-industry empirical evidence showing that net entry rates are on average very close to zero (see e.g. Malerba and Orsenigo, 1996; Bartelsman et al., 2005, and references therein).

${ }^{11}$ This is well in line with the empirical evidence on firm pricing behavior (see e.g. Fabiani et al., 2006).

12 The mark-up of capital-good firms is set at the same level as their R\&D investment propensity in all scenarios investigated in this paper (see the table in Appendix B for the parameterization of the "canonic" model).

${ }^{13}$ In Dosi et al. (2006) we checked the robustness of this assumption employing more sophisticated expectation-formation rules. We found that increasing the computational capabilities of firms does not have much influence on the dynamics of the economy and in particular does not improve either the average growth rates or the stability of the economy.
} 
production depends on the expected demand as well as on the difference between actual and desired inventories (i.e. a fraction of the expected demand). If the desired capital stock - dependent on the desired level of production - is higher than the current one, firms invest in order to expand their production capacity.

Consumption-good firms have a capital stock composed of heterogenous machines with different productivities associated with them. Firms decide whether to scrap their machines following a payback period rule, that is they assess whether the substitution cost of any current machine, i.e. the price of a new one, can be recovered in a given number of years by cutting production costs (new machines have lower unit production cost than incumbent ones). In this way, technical change and capital-good prices affect the replacement decisions of consumption-good firms. ${ }^{14}$ The latter choose their capital-good supplier comparing the price and productivity of those machine tools which they know via the brochures they receive. Machine production is a time-consuming process: consumption-good firms receive the ordered machines at the end of the period. ${ }^{15}$ Gross investment of each firm is the sum of expansion and replacement investment. Aggregate investment is just the sum of the investments of all consumption-good firms.

Given their current stock of machines, consumption-good firms compute their average productivity and unit costs of production. Firms fix prices applying a variable mark-up $\left(\mu_{j}\right)$ over the latter. The variation of such mark-ups are regulated by the dynamics of firms' market shares $\left(f_{j}\right)$ : firms raise (cut) mark-up whenever the growth rate of their market shares is positive (negative):

$$
\mu_{j}(t)=\mu_{j}(t-1)\left(1+v \frac{f_{j}(t-1)-f_{j}(t-2)}{f_{j}(t-2)}\right),
$$

with $0 \leq v \leq 1$. This process in turn implies that firms' mark-up rates fluctuate around a sort of peg represented by the initial mark-up rate $\bar{\mu}(0)$. Thus, by tuning up and down the level of such initial mark-up rate one can vary the long-term income distribution between wages and profits. In Sections 4.2 and 4.3, we shall indeed make extensive exercises studying how different mark-up rates affect the aggregate dynamics of an economy, and how the effects of different fiscal and monetary policies vary conditional on different levels of this variable.

Prices are one of the key determinants of firms' competitiveness. The other ones are the levels of unfilled demand. If firms cannot fully meet their demand quantities, their competitiveness is accordingly reduced.

Market shares evolve following a replicator-type dynamics operating under conditions of imperfect information, ${ }^{16}$ so that even if the product is homogeneous, firms may charge different prices. In such dynamics, firms with above-average competitiveness expand their market shares, while those below shrink it (or even die).

At the end of each period, consumption-good firms compute their profits $\left(\Pi_{j}\right)$ as:

$$
\Pi_{j}(t)=S_{j}(t)-P C_{j}(t)-r D e b_{j}(t),
$$

where $S_{j}(t)$ is turnover, $P C_{j}$ defines total production costs, $r$ is the interest rate, and Deb denotes the stock of firm debt. The investment choices of consumption-good firms and their profits determine the evolution of their stock of liquid assets $\left(N W_{j}\right)$

$$
N W_{j}(t)=N W_{j}(t-1)+\Pi_{j}(t)-c I_{j}(t)
$$

where $c I_{j}(t)$ is the amount of internal funds employed by firm $j$ to finance its investment and production expenditures in period $t$ (with $c I_{j}(t) \leq N W_{j}(t-1)$ ).

\subsection{Firm credit demand and the banking sector}

We assume a banking sector with only one commercial bank (or $n$ identical ones) that gathers deposits and provides credit to firms. In what follows, we first describe how credit demand is calculated by each firm. Next, we discuss how total credit is determined by the bank, and how it is allocated to each firm.

Consumption-good firms have to finance their investments as well as their production, as they advance worker wages. In line with a growing number of theoretical and empirical papers (e.g. Stiglitz and Weiss, 1992; Greenwald and Stiglitz, 1993; Hubbard, 1998), and in line with sheer intuition, we assume imperfect capital markets. This implies that the financial structure of firms matters (external funds are more expensive than internal ones) and firms may be credit rationed. Consumption-good firms finance production and investment using first their stock of liquid assets. If the latter does not fully cover total production and investment costs, firms borrow external funds from the bank. Total production and investment expenditures of firms must therefore satisfy the resource constraint

$$
c_{j}(t) Q_{j}(t)+E I_{j}^{d}(t)+R I_{j}^{d}(t) \leq N W_{j}(t-1)+C D_{j}(t),
$$

where $c_{j}(t) Q_{j}(t)$ is total production costs, $E I_{j}^{d}(t)$ is expansion investment, $R I_{j}^{d}(t)$ is replacement investment, $N W_{j}(t-1)$ is the stock of liquid assets, and $C D_{j}(t)$ is the credit demand by the firm. Firms have limited borrowing capacity: the maximum

\footnotetext{
${ }^{14}$ This in line with a large body of empirical papers (e.g. Feldstein and Foot, 1971; Eisner, 1972; Goolsbee, 1998) showing that replacement investment is typically not proportional to the capital stock.

15 The presence of gestation-lag effects in firm investments expenditures is supported by a large body of empirical literature (see e.g. Del Boca et al., 2008).

16 See Rotemberg (2008) for a survey of the empirical literature on consumers' imperfect price knowledge.
} 
credit demand of each firm is limited by its past sales according to a loan-to-value ratio $(0 \leq \lambda \leq \infty)$ :

$$
C D_{j}(t) \leq \lambda S_{j}(t-1) \text {. }
$$

Eqs. (4) and (5) introduce a "balance sheet" effect in the model (cf. Section 2) as they imply that an increase in either firm stock of liquid assets or in past sales may yield an increase of firm production and investment.

The maximum credit available in the economy is set through a credit multiplier rule. More precisely, in each period the bank is allowed by an unmodeled Central Bank to grant credit above the funds obtained through deposits from both capital- and consumption-good firms (and equal to their past stock of liquid assets, $N W_{i}$ and $N W_{j}$, respectively), according to a multiplier $k$. The maximum credit available in the economy at time $t, \operatorname{MTC}(t)$ is:

$$
\operatorname{MTC}(t)=k\left(\sum_{i=1}^{F 1} N W_{i}(t-1)+\sum_{j=1}^{F 2} N W_{j}(t-1)\right), \quad k>0 .
$$

Total credit is allocated to each firm in the consumption-good sector on a pecking order basis, according to the ratio between the stock of liquid assets and sales, $N W_{j}(t) / S_{j}(t)$. More precisely, the bank first ranks firms on the basis on their liquidity-to-sales ratio, and starts to satisfy the demand of the first firm in the rank, then the second one, etc. If the total credit available is insufficient to fulfill the demand of all the firms in the pecking order list, some firms that are lower in the pecking order are credit rationed. More precisely, let $\operatorname{Deb}_{j}(t)$ the stock of debt of the firm $j$ in period $t$. In every period we have $\operatorname{Deb}_{j}(t) \leq C D_{j}(t)$, with this last condition being satisfied with equality if the firm is not rationed in the credit market. Note that only firms that are not credit-rationed can fully satisfy their investment plans employing their stock of liquid assets first and then their borrowing capacity.

Conversely, the total demand for credit can also be lower than the total notional supply. In this case all credit demand of firms is fulfilled and there are no credit-rationed firms. It follows that in any period the stock of loans of the bank satisfies the following constraint:

$$
\sum_{j=1}^{F 2} \operatorname{Deb}_{j}(t)=\operatorname{Loan}(t) \leq \operatorname{MTC}(t)
$$

Eqs. (6) and (7) imply that the "balance sheet channel" and "bank lending channel" interact in the model. This is because the distribution of firm cash flows affects both the internal financing possibilities of production and investment and, through deposits, the provision of bank credit in the next period. In Section 4.3 we shall see how different monetary policies (interest rates, credit multipliers) impact on the foregoing interaction, and via the latter, transmit their effects to the economy.

The profits of the bank are equal to interest rate receipts from redeemable loans and from interests on reserves held at the Central Bank ${ }^{17}$ minus interests paid on deposits. Furthermore, the bank fixes its deposit $\left(r_{D}\right)$ and loan $\left(r_{L}\right)$ rates applying, respectively, a mark-down and a mark-up on the Central Bank rate $r^{18}$

$$
\begin{array}{ll}
r_{D}=\left(1-\psi_{D}\right) r, & 0 \leq \psi_{D} \leq 1, \\
r_{L}=\left(1+\psi_{L}\right) r, & 0 \leq \psi_{L} \leq 1 .
\end{array}
$$

The profits of the bank increase its reserves held at the Central Bank. Note that the bank holds excess reserves as a buffer against potential losses stemming from non-performing loans.

\subsection{The labor market}

We do not impose any assumption of labor-market clearing: as a consequence involuntary unemployment as well as labor rationing are the rule rather than the exception. The aggregate labor demand is computed summing up the labor demand of capital- and consumption-good firms. The aggregate supply is exogenous and inelastic. Aggregate employment is then the minimum between labor demand and supply. The wage is set according to

$$
w(t)=w(t-1)\left(1+\psi_{1} \frac{\Delta \overline{A B}(t)}{\overline{A B}(t-1)}+\psi_{2} \frac{\Delta c p i(t)}{c p i(t-1)}+\psi_{3} \frac{\Delta U(t)}{U(t-1)}\right),
$$

where $\overline{A B}$ is the average labor productivity, $c p i$ is the consumer price index, and $U$ is the unemployment rate. The wage rate is determined by institutional and market factors, with both indexation mechanisms upon consumption prices and average productivity, on the one hand, and, adjustments to unemployment rates, on the others. In Dosi et al. (2010), we explore different institutional regimes governing the relative importance of price, productivity and unemployment for wage setting. Indeed, the major qualitative properties of the model considered here are quite robust to regime

\footnotetext{
17 In the simulation exercises performed below, for simplicity the interest rate on reserves held at the Cental Bank is set to zero.

18 This formalization of the credit market implies that banks respond to changes in aggregate credit conditions by changing non-price terms of the loan (loan size in this case) rather than the interest rate. This is in line with recent empirical evidence (e.g. from Loan Officer Opinion Surveys, see Lown and Morgan, 2006).
} 
variations. Hence, here, for simplicity we restrict the analysis to a regime wherein wage just grows with average productivity. $^{19}$

\subsection{Consumption, taxes, and public expenditures}

The public sector levies taxes on firm profits and worker wages (or on profits only) and pays to unemployed workers a subsidy, that is a fraction of the current market wage. In fact, taxes and subsidies are the fiscal instruments that contribute to the aggregate demand management. All wages and subsidies are consumed: the aggregate consumption $(C)$ is the sum of income of both employed and unemployed workers, as the model satisfies the standard national account identities: the sum of value added of capital- and consumption-goods firms $(Y)$ equals their aggregate production since in our simplified economy there are no intermediate goods, and that in turn coincides with the sum of aggregate consumption, investment and change in inventories $(\Delta N)$

$$
\sum_{i=1}^{F_{1}} Q_{i}(t)+\sum_{j=1}^{F_{2}} Q_{j}(t)=Y(t) \equiv C(t)+I(t)+\Delta N(t) .
$$

The micro decisions of a multiplicity of heterogenous, adaptive agents and their interaction mechanisms is the explicit microfoundation of the dynamics for all aggregate variables of interest (e.g. output, investment, employment, etc.). It is important to emphasize, however, that the aggregate properties of the economy do not bear any apparent isomorphism with micro adjustment rules outlined above. And a fundamental consequence is also that any "representative agent" compression of micro heterogeneity is likely to offer a very distorted account of both what agents do and of the collective outcomes of their actions_indeed, well in tune with the arguments of Kirman (1992) and Solow (2008).

\section{Simulation results}

Similarly to Dosi et al. (2010), we investigated the micro and macro properties of the model described in the previous section through extensive computer simulations. ${ }^{20}$ We undertake the simulation analysis of the model in two complementary steps. First, we identify a "benchmark" setup for which the model is empirically validated, i.e. it is able to replicate a wide spectrum of microeconomic and macroeconomic stylized facts. Next, we turn to "policy experiments", by identifying sets of parameters (e.g. the interest rate, the credit multiplier, the tax rate) whose values capture different policies. Under the "policy experiment mode", in Dosi et al. (2010), we studied the consequences of different "innovation regimes" - and related policies - and their interaction with (Keynesian) demand management. In this paper, we turn to experiments with different income distribution regimes and different fiscal and monetary policies, and we analyze their impact on a long list of indicators including output growth rates, output volatility, frequency of full employment and unemployment rates, likelihood of crises (defined as number of episodes with output growth rates lower than $-3 \%$ ). ${ }^{21}$ All results presented in the following sections refer to Montecarlo averages over 50 iterations of $T=600$ time steps each. ${ }^{22}$ The benchmark parameterization is reported in Appendix B.

\subsection{Empirical validation}

Let us now consider the results of the empirical validation of the model. The macro and micro stylized facts robustly replicated by the model are the same statistical regularities produced by and discussed at much greater length in Dosi et al. (2010) plus a few other finance-related ones. ${ }^{23}$ To repeat our earlier results, the model is able to generate macroeconomic series of output, consumption and aggregate investment characterized by self-sustained growth patterns (cf. Fig. 1) and by persistent fluctuations (see also Fig. 2 and Table 1). Moreover, aggregate investment is more volatile than GDP whereas consumption is less volatile. In addition, the model replicates the empirically observable co-movements between a large

\footnotetext{
${ }^{19}$ In these circumstances, since firms' average mark-up is pegged to the initial one (see Eq. (3) and discussion above), this regime is also characterized by a zero average inflation rate. We experimented with regimes wherein wages move also as a function of unemployment rates. All the properties discussed below, robustly hold. Note, however, that this does not imply that the regimes of regulation of the labor market and of wages are irrelevant for the dynamic properties of the system. On the contrary, as we discuss in Napoletano et al. (2012), primarily market-driven vs. institutionally regulated forms of wage formation do matter a lot in terms of macrodynamics.

${ }^{20}$ We implement the model in C+ employing Robert Davies' NEWMAT library for matrix handling. The code is available from the authors upon request. An user-friendly version of the model together with its code and a Java applet will soon be available for distribution on a dedicated website.

${ }^{21}$ Interestingly, many statistical regularities concerning the structure of the economy (e.g. firm size distributions, distributions of firms growth rates, etc.) appear to hold across an ample parameter range, under positive technological progress, even when policies undergo the changes we study in the following.

${ }^{22}$ Extensive tests show that results of the model are significantly robust to changes in the initial conditions for the microeconomic variables of the model. In addition, they show that, for the majority of the statistics under study, Montecarlo distributions are sufficiently symmetric and unimodal. This justifies the use of across-run averages as meaningful indicators. All our results do not significantly change if one increases Montecarlo sample sizes.

23 See Stock and Watson (1999), Napoletano et al. (2006), and Claessens et al. (2009) for the empirical properties of the macroeconomic time series; and Dosi (2007) and Bartelsman and Doms (2000) for an account of the main stylized facts concerning firm and productivity dynamics.
} 


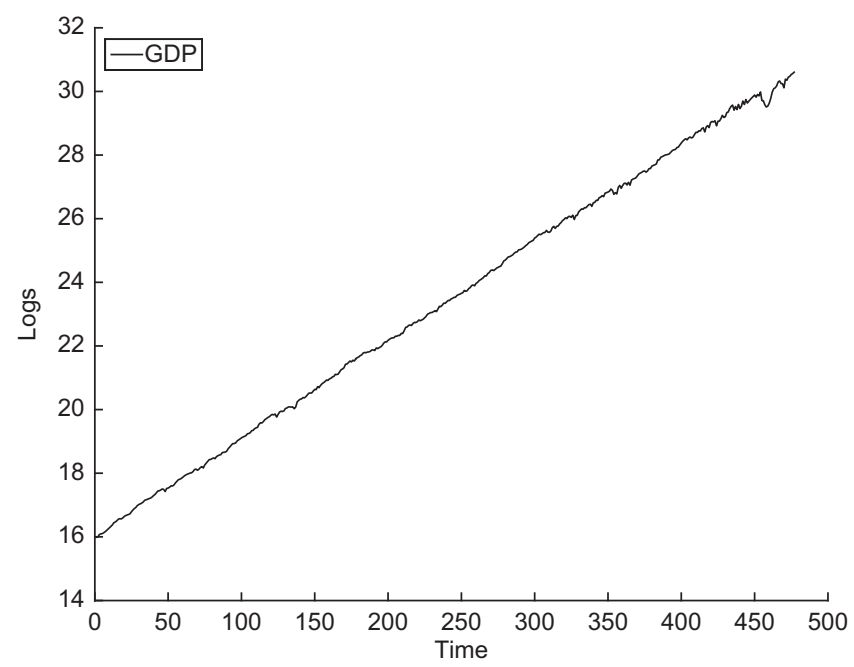

Fig. 1. Log of GDP time series.

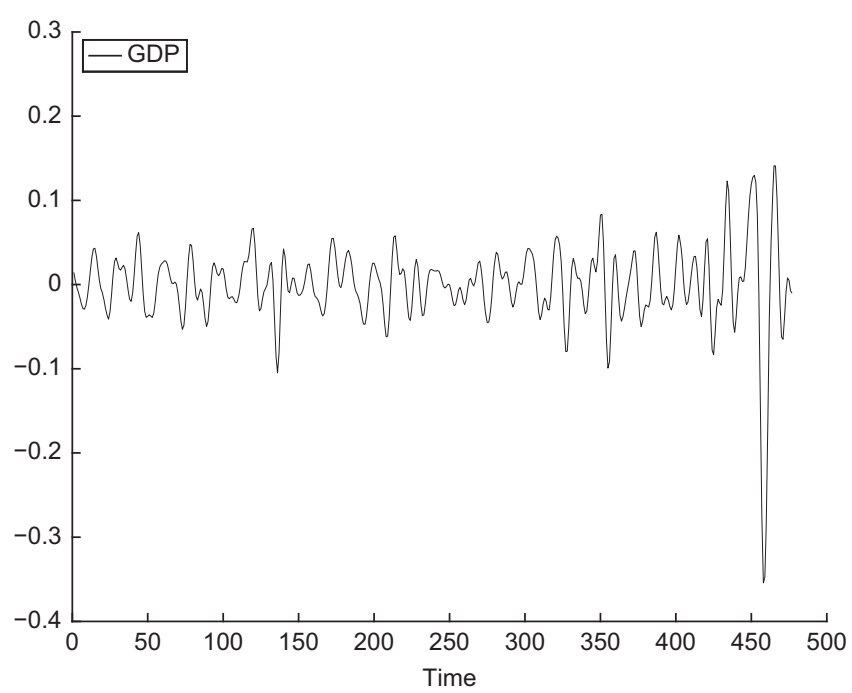

Fig. 2. Bandpass filtered GDP series.

set of macro time series and GDP (net investment and consumption pro-cyclical and coincident, inflation pro-cyclical and lagging, counter-cyclical mark-up rates, etc.).

At the same time, at the microeconomic level, the model matches a wide set of stylized facts concerning firm dynamics (including right-skewed distribution of firm sizes, fat-tailed distributions of firm growth rates, wide and persistent productivity differences across firms, lumpy investment dynamics).

However, the credit-enhanced $\mathrm{K}+\mathrm{S}$ model is also able to match the empirical evidence about credit dynamics (see Claessens et al., 2009). As shown in Table 1, the model generates a highly pro-cyclical aggregate firm debt dynamics. Second, cross-correlation values shed light on the characteristics of credit dynamics underneath the business cycles endogenously generated by the model, and on the strong "Minskian" features of the emerging outcomes (see e.g. Minsky, 1986). Indeed, bank deposits (equal to total firms' stock of liquid assets) are counter-cyclical and lagging GDP. Supplied credit displays the same cyclical behavior and interestingly it is positively correlated with future values of GDP (cf. Table 1), in line with empirical evidence it indicates that expansions in supplied credit anticipate future expansions in aggregate output. Third, the liquidity-to-sales ratio (proxying credit rating in the model) is counter-cyclical and lagging, whereas bankruptcy rates are pro-cyclical and coincident.

These patterns are coherent with the characteristics of the "credit cycles" observed in real data (see Lown and Morgan, 2006; Leary, 2009). Higher production and investment expenditures induce a rise in firms debt. In turn, this gradually 
Table 1

Correlation structure for output and credit structure. Bpf: bandpass filtered $(6,32,12)$ series. Monte-Carlo simulation standard errors in parentheses.

\begin{tabular}{|c|c|c|c|c|c|c|c|c|c|}
\hline \multirow[t]{2}{*}{ Series (Bpf) } & \multicolumn{9}{|c|}{ Output (Bpf) } \\
\hline & $t-4$ & $t-3$ & $t-2$ & $t-1$ & $t$ & $t+1$ & $t+2$ & $t+3$ & $t+4$ \\
\hline GDP & $\begin{array}{l}-0.0237 \\
(0.0133)\end{array}$ & $\begin{array}{c}0.2704 \\
(0.0108)\end{array}$ & $\begin{array}{c}0.6116 \\
(0.0064)\end{array}$ & $\begin{array}{c}0.8903 \\
(0.0021)\end{array}$ & $\begin{array}{c}1 \\
(0)\end{array}$ & $\begin{array}{c}0.8903 \\
(0.0021)\end{array}$ & $\begin{array}{c}0.6116 \\
(0.0064)\end{array}$ & $\begin{array}{c}0.2704 \\
(0.0108)\end{array}$ & $\begin{array}{l}-0.0237 \\
(0.0133)\end{array}$ \\
\hline Total firm debt & $\begin{array}{c}0.2181 \\
(0.0216)\end{array}$ & $\begin{array}{c}0.3991 \\
(0.0207)\end{array}$ & $\begin{array}{c}0.5726 \\
(0.0194)\end{array}$ & $\begin{array}{c}0.6931 \\
(0.0179)\end{array}$ & $\begin{array}{c}0.7178 \\
(0.0166)\end{array}$ & $\begin{array}{c}0.6321 \\
(0.0154)\end{array}$ & $\begin{array}{c}0.4568 \\
(0.0146)\end{array}$ & $\begin{array}{c}0.2376 \\
(0.0146)\end{array}$ & $\begin{array}{c}0.0259 \\
(0.0151)\end{array}$ \\
\hline Bank deposits & $\begin{array}{l}-0.3420 \\
(0.0219)\end{array}$ & $\begin{array}{l}-0.2646 \\
(0.0238)\end{array}$ & $\begin{array}{l}-0.1603 \\
(0.0241)\end{array}$ & $\begin{array}{l}-0.0599 \\
(0.0220)\end{array}$ & $\begin{array}{c}0.0158 \\
(0.0188)\end{array}$ & $\begin{array}{c}0.0654 \\
(0.0165)\end{array}$ & $\begin{array}{c}0.1003 \\
(0.0153)\end{array}$ & $\begin{array}{c}0.1326 \\
(0.0145)\end{array}$ & $\begin{array}{c}0.1639 \\
(0.0138)\end{array}$ \\
\hline Credit supplied & $\begin{array}{l}-0.3420 \\
(0.0219)\end{array}$ & $\begin{array}{c}-0.2646 \\
(0.0238)\end{array}$ & $\begin{array}{l}-0.1603 \\
(0.0241)\end{array}$ & $\begin{array}{l}-0.0599 \\
(0.0220)\end{array}$ & $\begin{array}{c}0.0158 \\
(0.0188)\end{array}$ & $\begin{array}{c}0.0654 \\
(0.0165)\end{array}$ & $\begin{array}{c}0.1003 \\
(0.0153)\end{array}$ & $\begin{array}{c}0.1326 \\
(0.0145)\end{array}$ & $\begin{array}{c}0.1639 \\
(0.0138)\end{array}$ \\
\hline Liquidity-to-sales ratio & $\begin{array}{l}-0.3571 \\
(0.0200)\end{array}$ & $\begin{array}{l}-0.5081 \\
(0.0207)\end{array}$ & $\begin{array}{l}-0.6150 \\
(0.0216)\end{array}$ & $\begin{array}{l}-0.6386 \\
(0.0207)\end{array}$ & $\begin{array}{l}-0.5599 \\
(0.0179)\end{array}$ & $\begin{array}{l}-0.3946 \\
(0.0148)\end{array}$ & $\begin{array}{l}-0.1851 \\
(0.0136)\end{array}$ & $\begin{array}{c}0.0184 \\
(0.0142)\end{array}$ & $\begin{array}{c}0.1768 \\
(0.0147)\end{array}$ \\
\hline Bankruptcy rate & $\begin{array}{l}-0.0112 \\
(0.0146)\end{array}$ & $\begin{array}{c}0.0645 \\
(0.0199)\end{array}$ & $\begin{array}{c}0.1656 \\
(0.0243)\end{array}$ & $\begin{array}{c}0.2721 \\
(0.0258)\end{array}$ & $\begin{array}{c}0.3522 \\
(0.0234)\end{array}$ & $\begin{array}{c}0.3757 \\
(0.0175)\end{array}$ & $\begin{array}{c}0.3305 \\
(0.0106)\end{array}$ & $\begin{array}{c}0.2292 \\
(0.0098)\end{array}$ & $\begin{array}{c}0.1042 \\
(0.0149)\end{array}$ \\
\hline
\end{tabular}

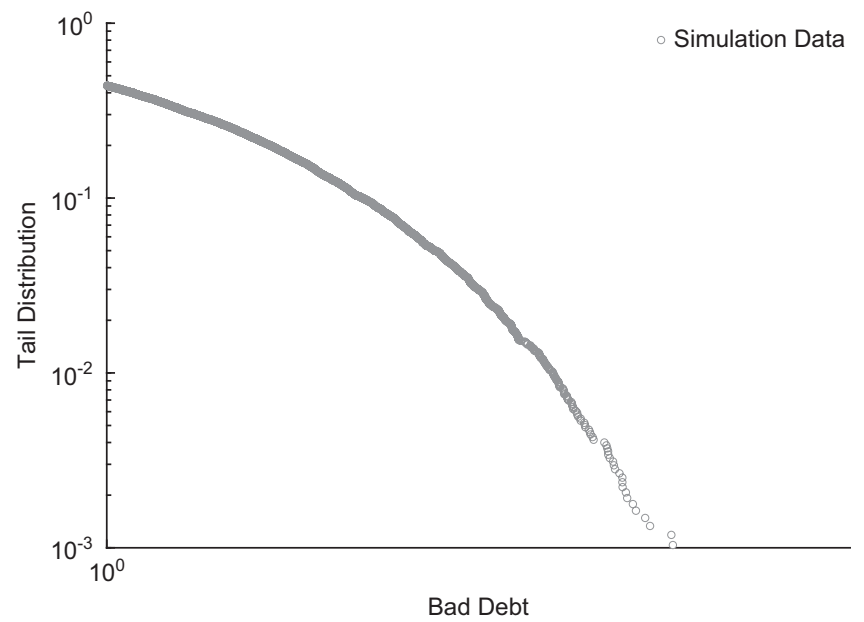

Fig. 3. Cross-sectional distribution of firms bad debt.

erodes firms' net cash flows and, as a consequence, credit supply. Accordingly, credit rationing increases. Higher credit constraints on firms reduce investment expenditures and set the premises for the incoming recessionary phase.

At the micro level, we have analyzed bankruptcy rates. The recent evidence on this issue (e.g. Fujiwara, 2004; Di Guilmi et al., 2004) has pointed out that the distribution by firm of the amounts of "bad" debt at the time of bankruptcy is highly skewed to the right and heavy tailed, displaying a power-law type behavior (clearly implying that episodes of large bankruptcies are statistically more frequent than what would be predicted by a normal distribution). As Fig. 3 clearly shows, this evidence is well replicated by our model. Moreover, we also find, in tune with the empirics, that the temporal distribution of bankruptcies is right skewed, displaying clustering in time (indeed the "crises").

\subsection{Income distribution, fiscal policies, growth and business cycles}

The role played by mark-up rates in the dynamics of the model is twofold. On the one hand, the level of the mark-up determines the profits of the firms, and thus the level of internal resources available to finance production and investment expenditures. Higher mark-ups imply - ceteris paribus - higher profits and thus a lower dependence of firms on the external financing provided by banks. On the other hand, the mark-up regulates the distribution of income between profits and wages. Since aggregate consumption in the model is equal to total wages, higher mark-up rates result in a lower level of demand for final-good firms.

In light of these contrasting effects we explore the impact of different income distribution regimes on aggregate dynamics by varying the long-term levels of the mark-ups themselves. Fig. 4 shows that the time the economy spends in full employment is inversely related to the mark-up rates. The more the functional distribution of income is biased towards profits, the less the economy spends time in full employment. 


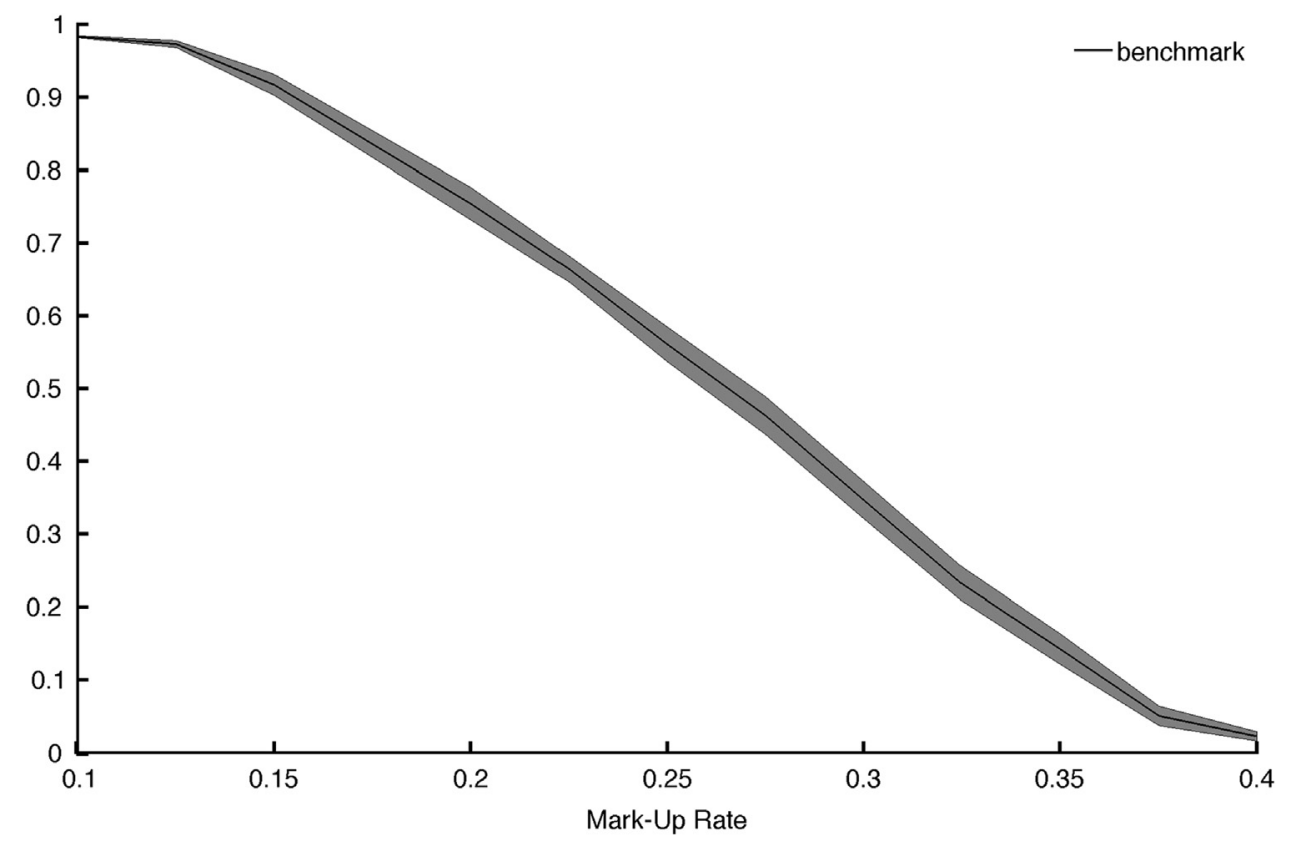

Fig. 4. Frequency of full employment and the mark-up rates (95\% confidence bands in gray).

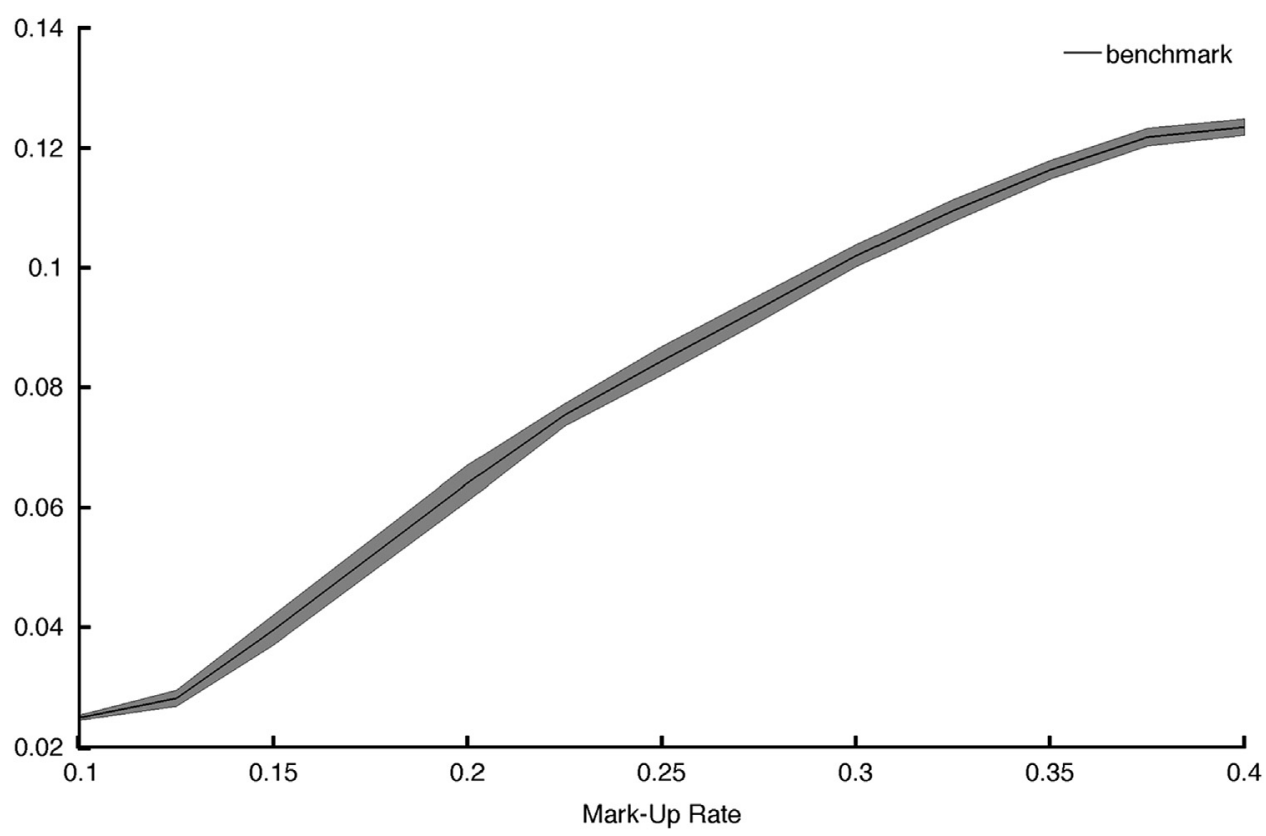

Fig. 5. Standard deviation of GDP growth rate and the mark-up rates ( $95 \%$ confidence bands in gray).

Figs. 5-7 reveal some further interesting features of such "non-Say" economies. First, the volatility of GDP growth (Fig. 5) is positively related to the mark-up rate. Second, the incidence of crises (cf. Fig. 6) and relatively high unemployment states (cf. Fig. 7) are also higher.

The above patterns notwithstanding, the long-term average GDP growth rates (Fig. 8) are only marginally (negatively) affected by the levels of mark-ups. Note however that the result is obtained in the "benchmark" scenario, which includes a positive degree of fiscal redistributive policy (tax rates on profits of $10 \%$ redistributed as unemployment subsidies). If we repeat the same experiment with tax and unemployment subsidies both set to zero (see Fig. 9), a pattern starkly emerges: 


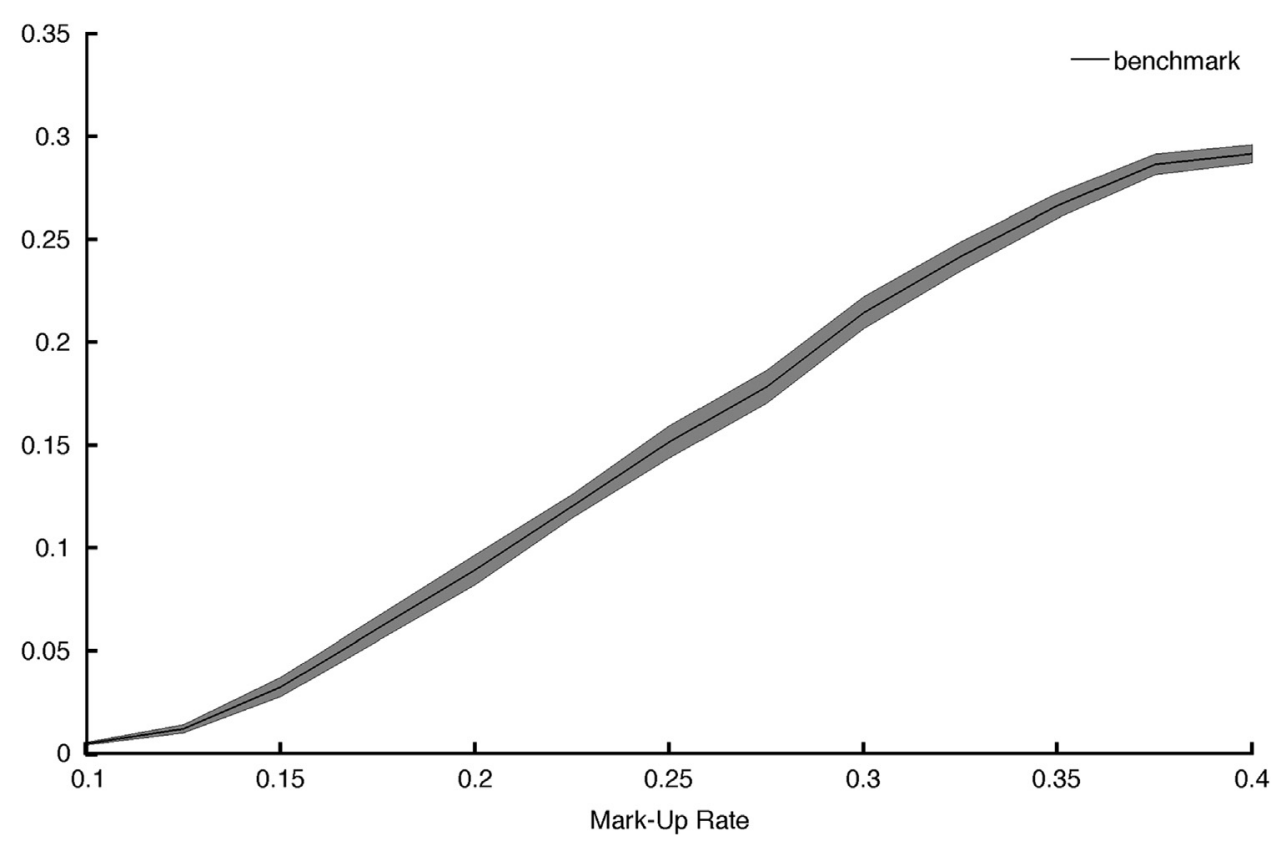

Fig. 6. Likelihood of crises in GDP and the mark-up rate (95\% confidence bands in gray). Note: Crises are defined as episodes with growth rates lower than - $3 \%$.

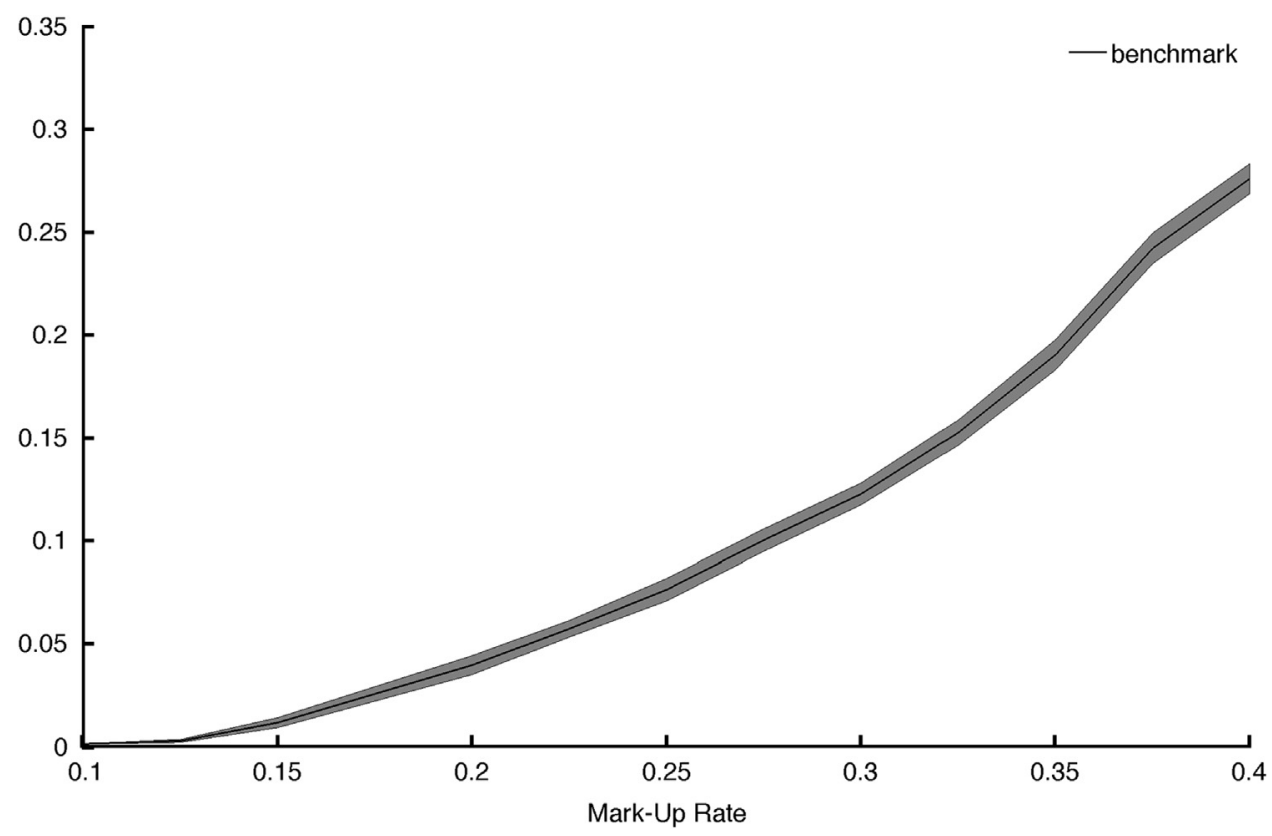

Fig. 7. Unemployment rate and the mark-up rate (95\% confidence bands in gray).

if fiscal policies are absent, the adverse effects of the mark-up rate on the frequency of full employment states are enormously strengthened.

The above findings generalize previous results from Dosi et al. (2010) on the role of fiscal policy in sustaining the longterm growth: the effectiveness of fiscal policy indeed increases with the mark-up levels. When the profit margin is very high, redistributive fiscal policies become a necessary condition for long-run growth. As in Dosi et al. (2010), redistributive policies act as a sort of parachute when the economy experiences unemployment, by avoiding excessive falls in consumption demand due to the reduced incomes of unemployed workers. Moreover, investment expectations in the model are linked to consumer demand. Hence, more stable consumption demand profiles enhance the incentives of firms to invest in new capacity and in new machines. 


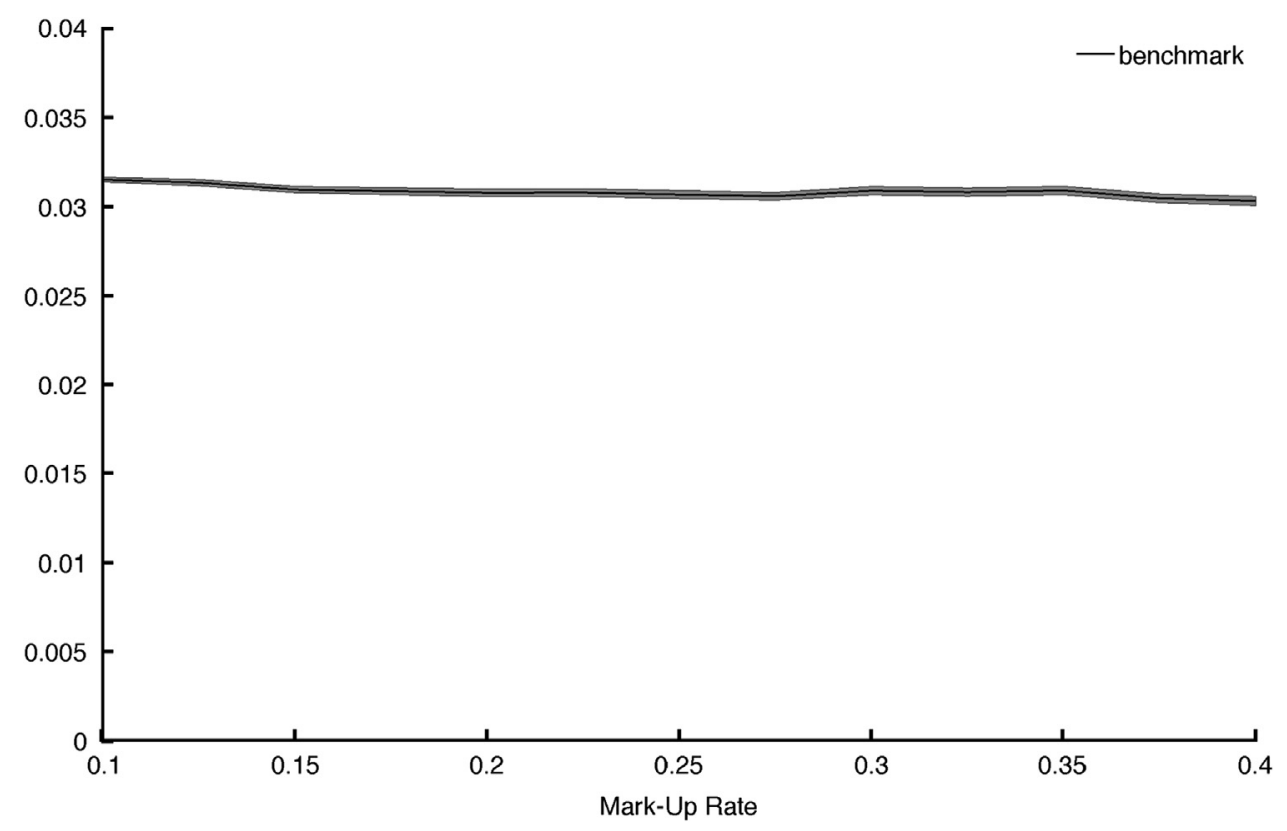

Fig. 8. Average GDP growth rate and the mark-up rate (95\% confidence bands in gray).

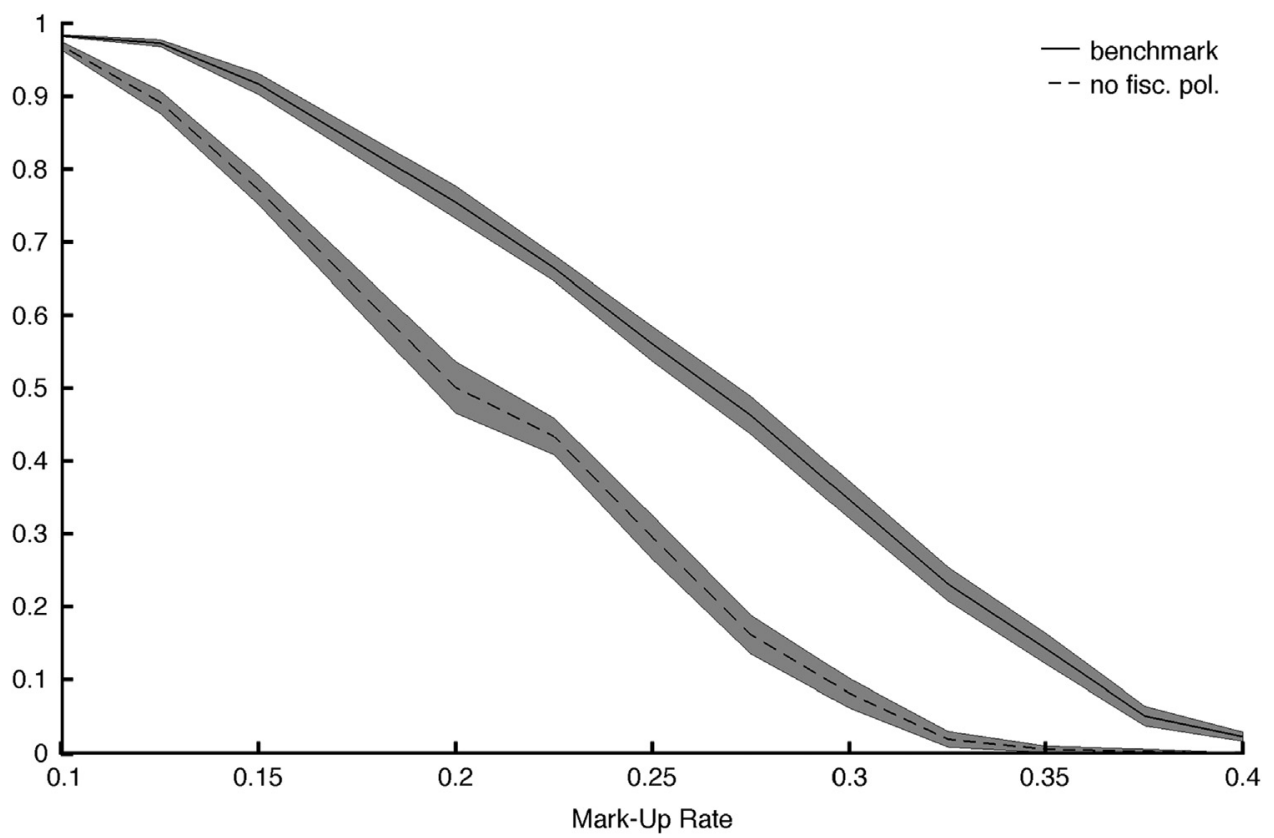

Fig. 9. Frequency of full employment in the benchmark scenario (solid line) and in the scenario with zero fiscal policy (dashed line; $95 \%$ confidence bands in gray).

When the mark-up rate is low, the distribution of income is obviously in favor of wages. This implies a high propensity to consume and a high "investment accelerator". As a consequence, the economy is most of the time in full employment. In contrast, when the profit margin is high, redistributive fiscal policies sustain an otherwise depressed consumer demand. This guarantees a higher long-run rate of growth.

Let us get deeper into the investigation of the interactions between fiscal policies and income distribution regimes. Let we define three scenarios according to the level of the initial mark-up rate $(0.10 ; 0.20 ; 0.40)$ in the consumption-good sector, and change at the same time both the tax $(t)$ (on profits only) and the unemployment-subsidy rates $\left(w_{u}\right)$ in the range between 0.15 and 0.90 . Notice that, all the fiscal policy experiments discussed below have been performed under conditions of on average balanced-budget of government finances. Results are reported in Figs. 10-15. 


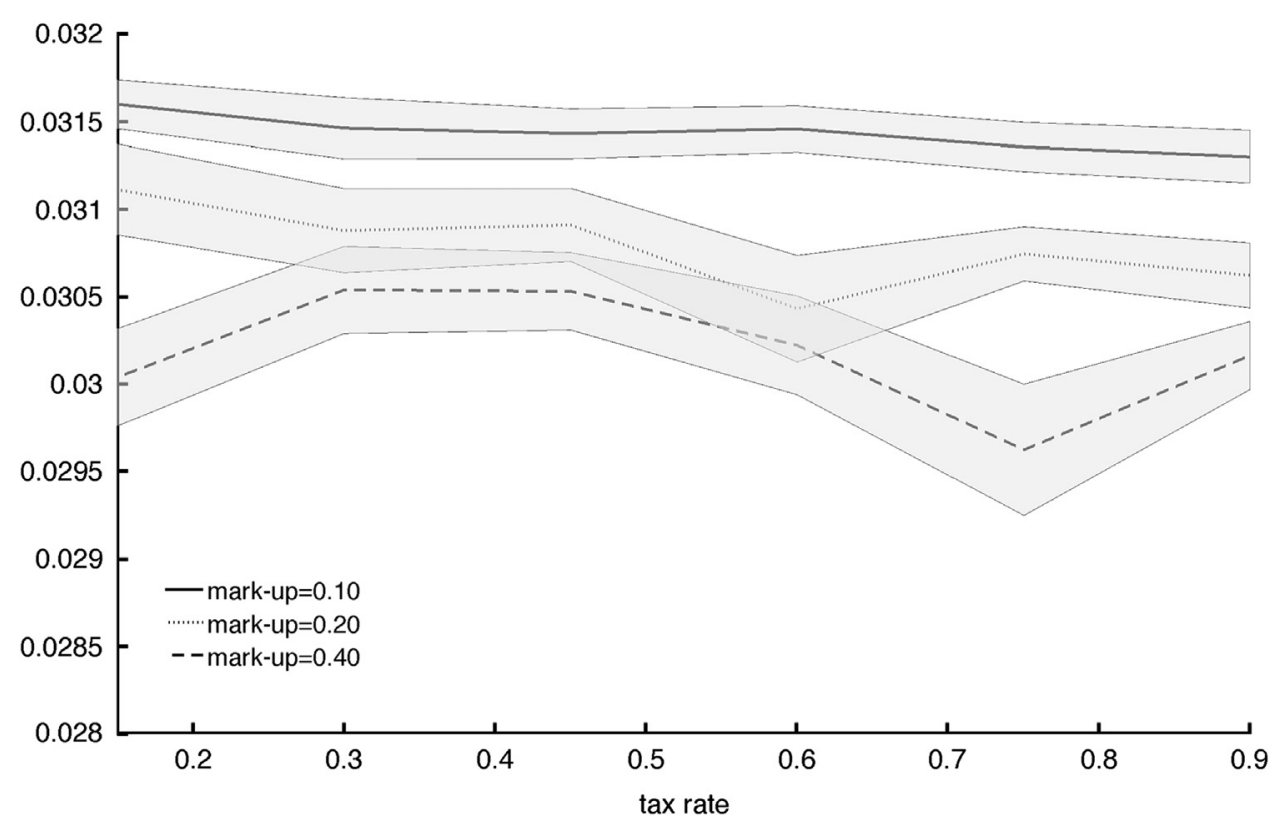

Fig. 10. Average GDP growth rate and the tax/unemployment-subsidy rates ( $95 \%$ confidence bands in gray).

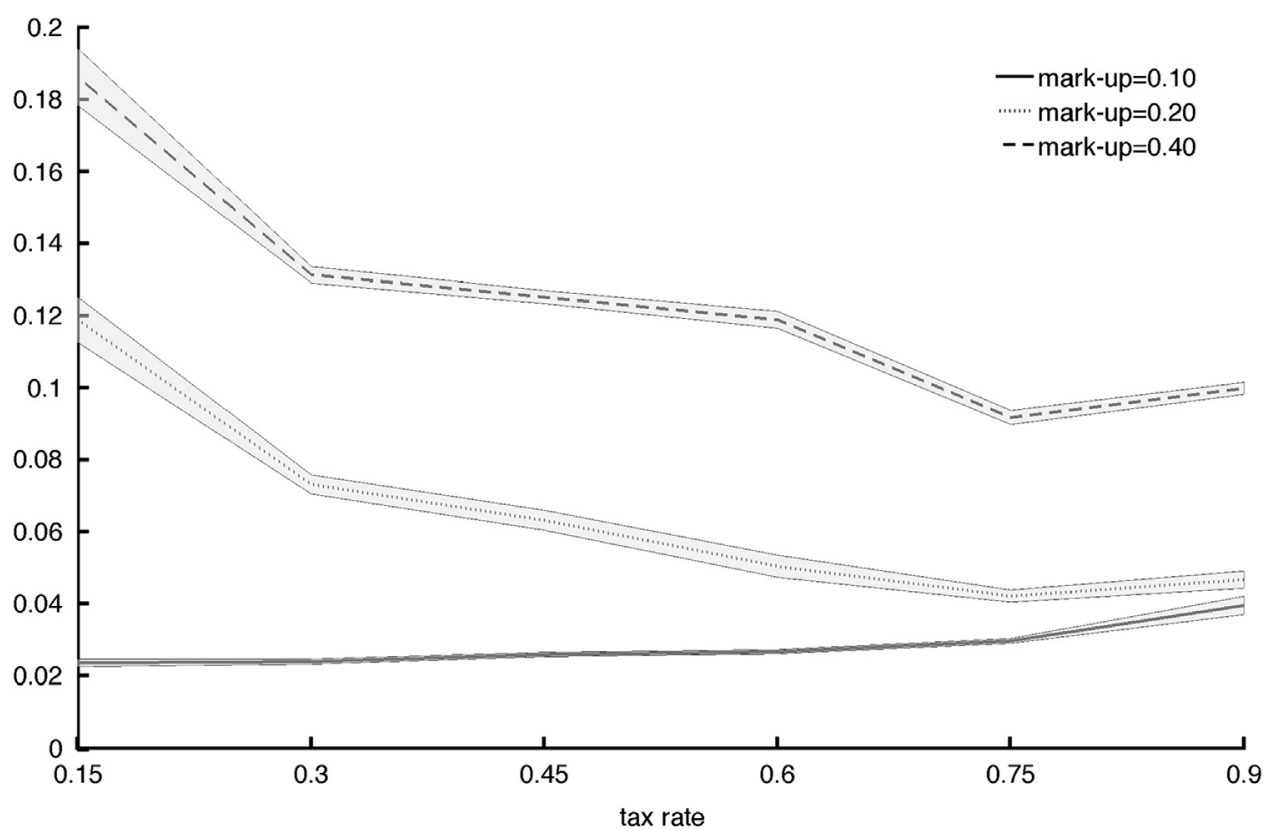

Fig. 11. Standard deviation of GDP growth rate and the tax/unemployment-subsidy rates (95\% confidence bands in gray).

In all the three mark-up scenarios, the average growth rate is not significantly affected by changes in both the tax rates and the unemployment-subsidy (see Fig. 10). In contrast, the volatility of the economy and the incidence of crises are strongly reduced by higher unemployment subsidy/tax rates (cf. Figs. 11 and 15). Notice also that the effects of fiscal policies change according to the mark-up conditions. Indeed, the capability of stronger redistributive policies to dampen business-cycle fluctuations increase when income distribution is more skewed toward profits.

The same patterns emerge also on the labor market side. If income distribution strongly favors wages (i.e. $\bar{\mu}(0)=0.10$ ), the economy spends most of the time in full employment for every possible couples of tax and unemployment-subsidy (see Fig. 13). Of course this results in an average unemployment rate close to zero (cf. Fig. 12). For higher mark-up levels (i.e. $\bar{\mu}(0)=0.20 ; 0.40$ ), higher doses of redistributive fiscal policies are required to stabilize the economy toward its full employment states. 


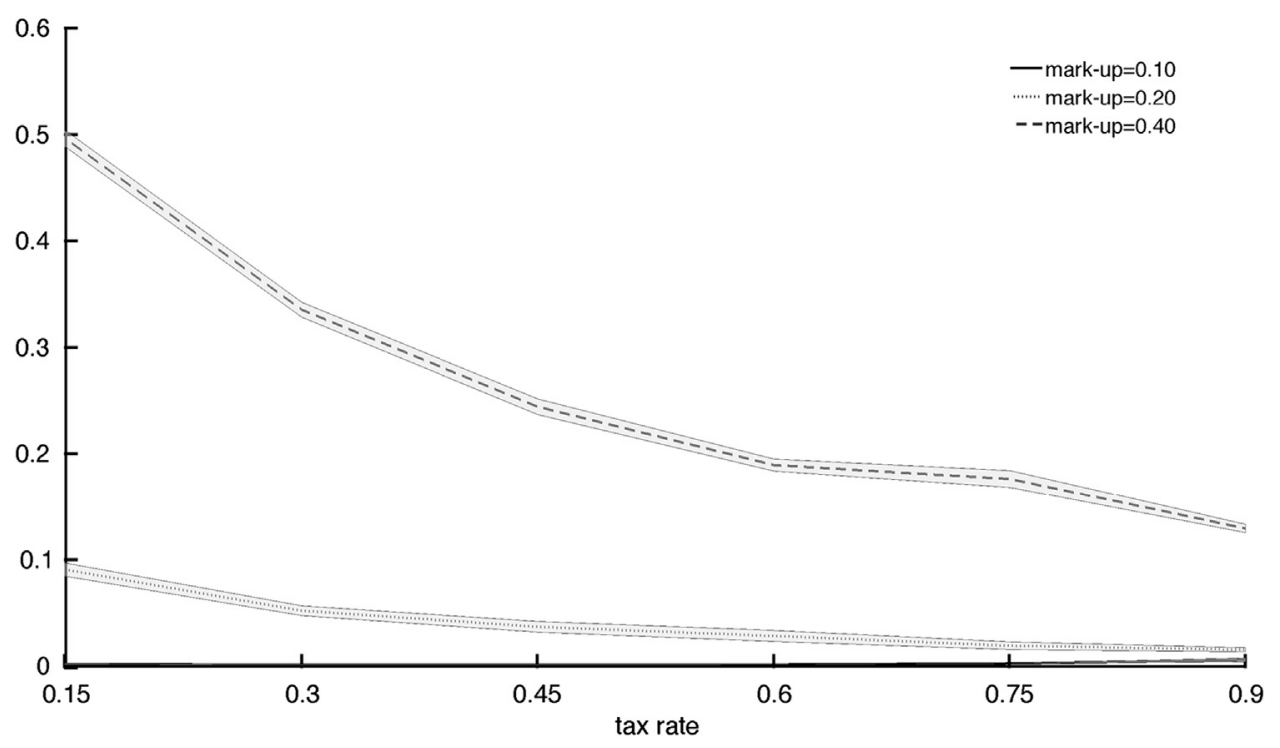

Fig. 12. Unemployment rate and the tax/unemployment-subsidy rates ( $95 \%$ confidence bands in gray).

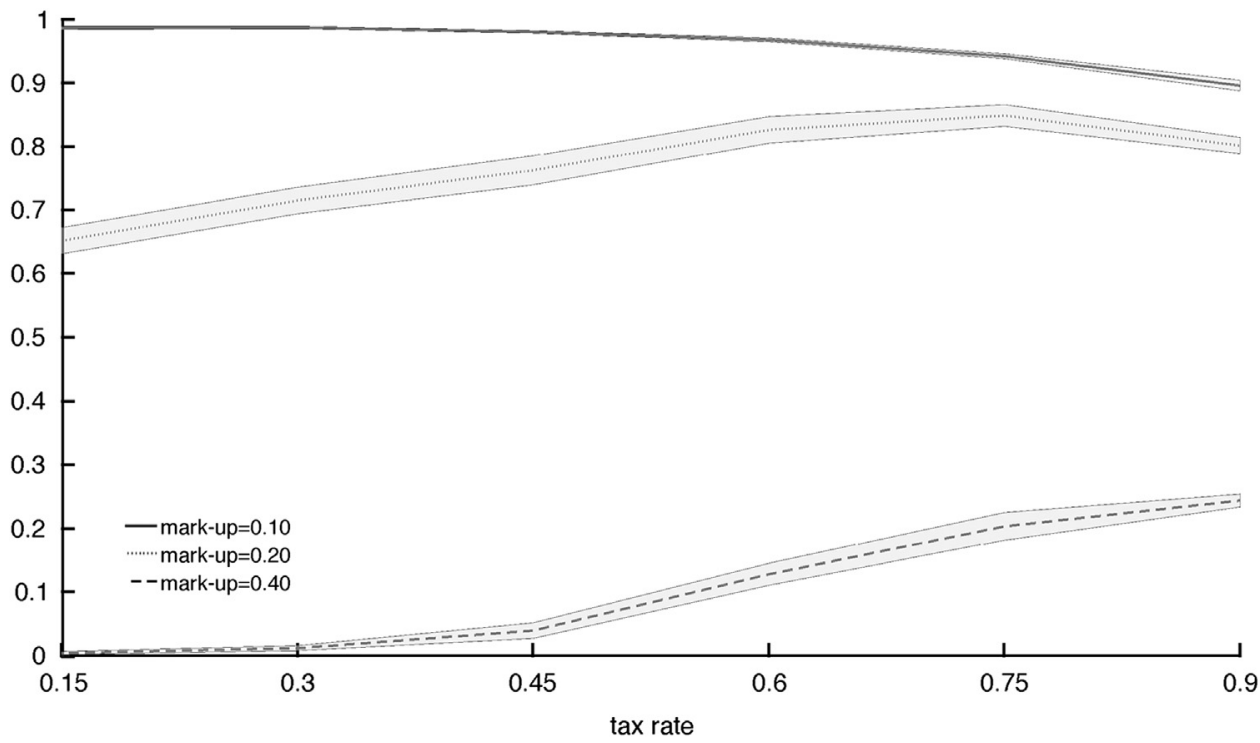

Fig. 13. Frequency of full employment states and tax/unemployment-subsidy rates (95\% confidence bands in gray).

Somewhat counterintuitively, average bankruptcy rates (Fig. 14) are positively influenced by higher levels of tax and unemployment subsidies. Our conjecture is that this occurs because very strong redistributive fiscal policies while fostering consumption demand also foster in turn firm investment, leading (extrapolatively adaptive) firms to build up what eventually will turn out to be excess productive capacity.

Overall, the results obtained in the three profit margin scenarios vindicate the importance of the interactions between income distribution regimes and redistributive fiscal policies. In fact, expansionary policies happen to be even more needed under profit-biased income distributions. Incidentally, more or less the opposite to what EMU countries are currently trying to do!

Let us now turn to the effects of monetary policies.

\subsection{Monetary policy}

To repeat, the level of mark-up rate has contrasting effects on firms behaviors. On one hand, higher mark-ups imply - other things being equal - higher net profits and thus less dependence on external financing. On the other hand, they 


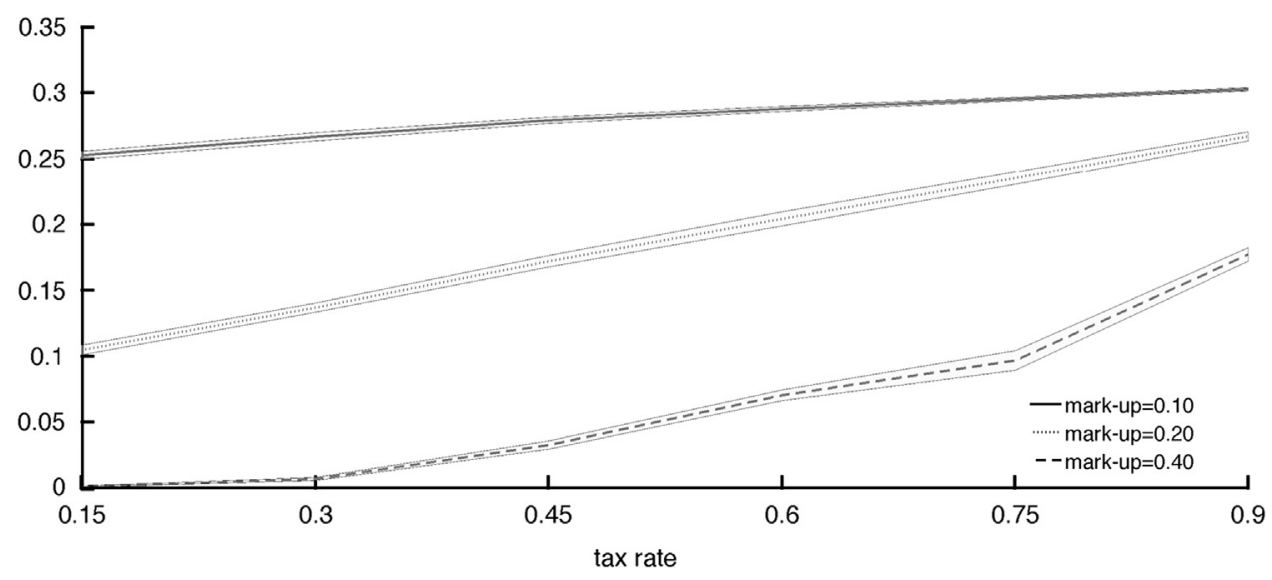

Fig. 14. Bankruptcy rate and tax/unemployment-subsidy rates (95\% confidence bands in gray).

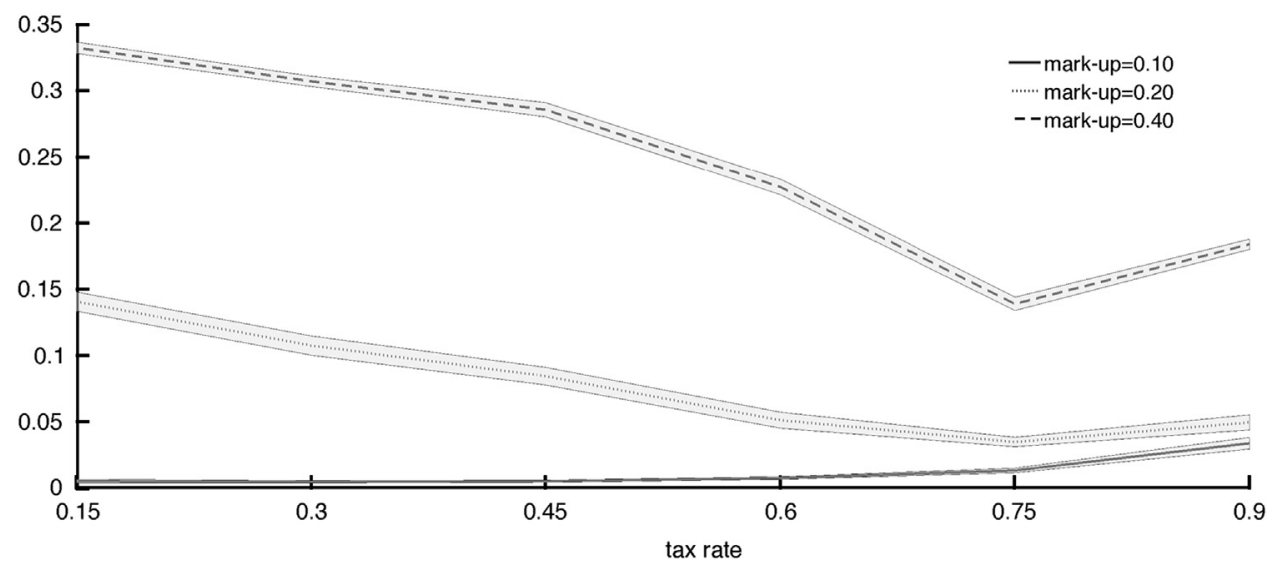

Fig. 15. Likelihood of crises in GDP growth and tax/unemployment-subsidy rates (95\% confidence bands in gray).

imply lower wage shares in the GDP and weaken consumption demand, with a consequent lower incentive for firms to invest. Thus, similarly to fiscal policy experiments, we ran experiments on monetary policy variables for different values of the initial mark-up rate $(0.10,0.20,0.40)$, in order to explore the effects of monetary policies under different income distribution regimes. We focus on the impact of two different policy instruments, first, the interest rate and, second, reserve requirements and thus credit multipliers.

Interest rates: As implied by the pricing behavior of the firms in the model, we focus here on a regime wherein inflation is on average zero, and we therefore rule out inflation targeting concerns. In fact, easy modifications would allow for inflationary pressures due to e.g. over-indexation of wages to prices, "over-sensitivity" of wages to unemployment rates, or, conversely, overshooting of output prices to unit costs. However, nothing seems to hint at any emergent "quantity theory" on money supply and prices. In addition, we make the extreme assumption that the Central Bank sets the initial level of the baseline interest rate and commits itself to keep it fixed throughout the simulation.

Figs. 16 and 17 show the average GDP growth rate and its standard deviation as a function of the baseline interest rate $r$, for different mark-up levels. Both average growth and volatility are completely unaffected by changes in the interest rate in the high mark-up scenario (0.40).

In contrast, significant effects emerge in the "benchmark" and low mark-up scenarios (respectively, 0.20 and 0.10 ; see again Appendix B for the benchmark parameterization). In these cases, the system displays two phases (i.e. two regimes). The interest rate does not change average growth and volatility up to a threshold above which average growth decreases and volatility increases with the interest rate (see Figs. 16 and 17). In addition, the threshold above which the interest rate affects growth and volatility decreases with the mark-up level.

The patterns displayed by other real variables in the model are similar to the ones just considered. Interest rates have no effects on the average unemployment rate (Fig. 19) and on the likelihood of crises (Fig. 18), if the mark-up is very high (in the simulation here 0.40). At lower levels, interest rates affect unemployment and the likelihood of crises above a given threshold value, with both unemployment and the probability of crises steadily increasing with interest rates themselves. 


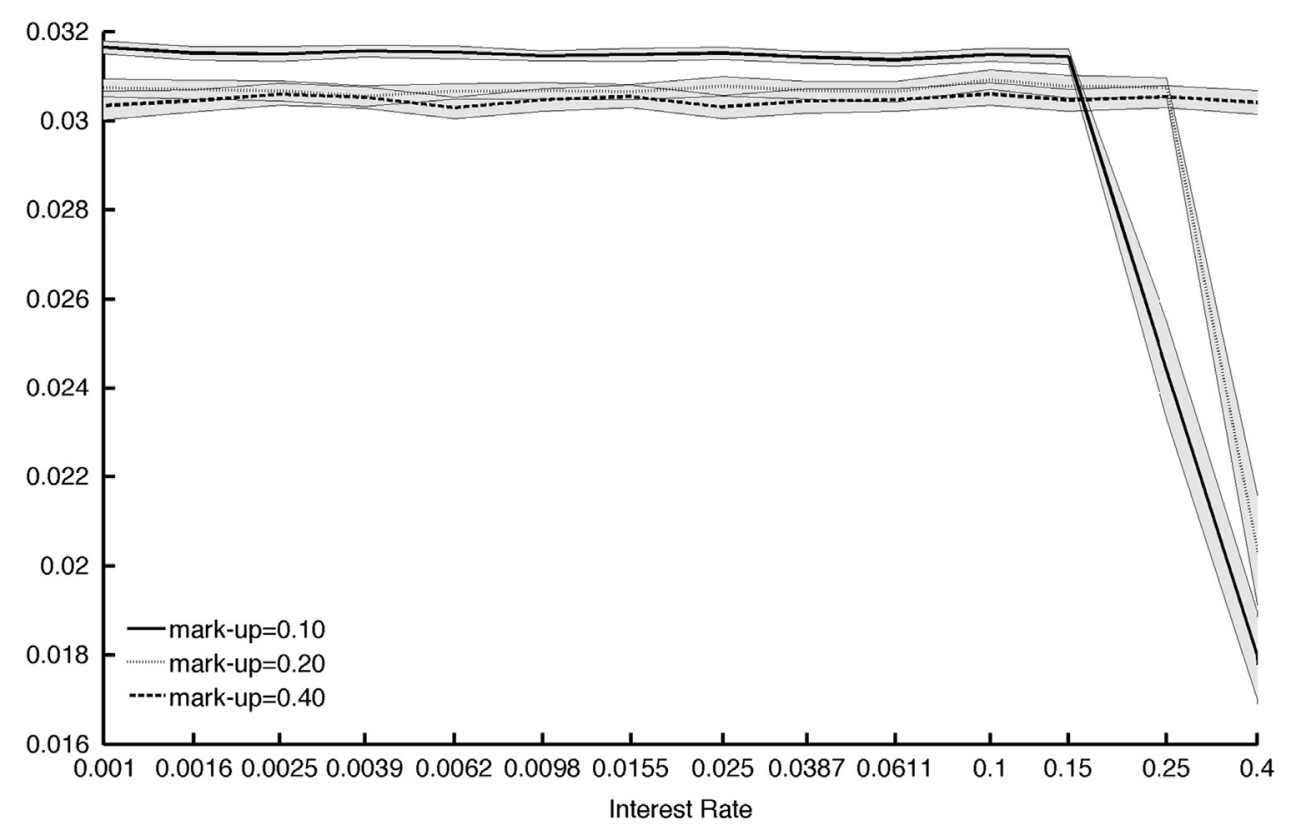

Fig. 16. Average GDP growth and the interest rate (95\% confidence bands in gray).

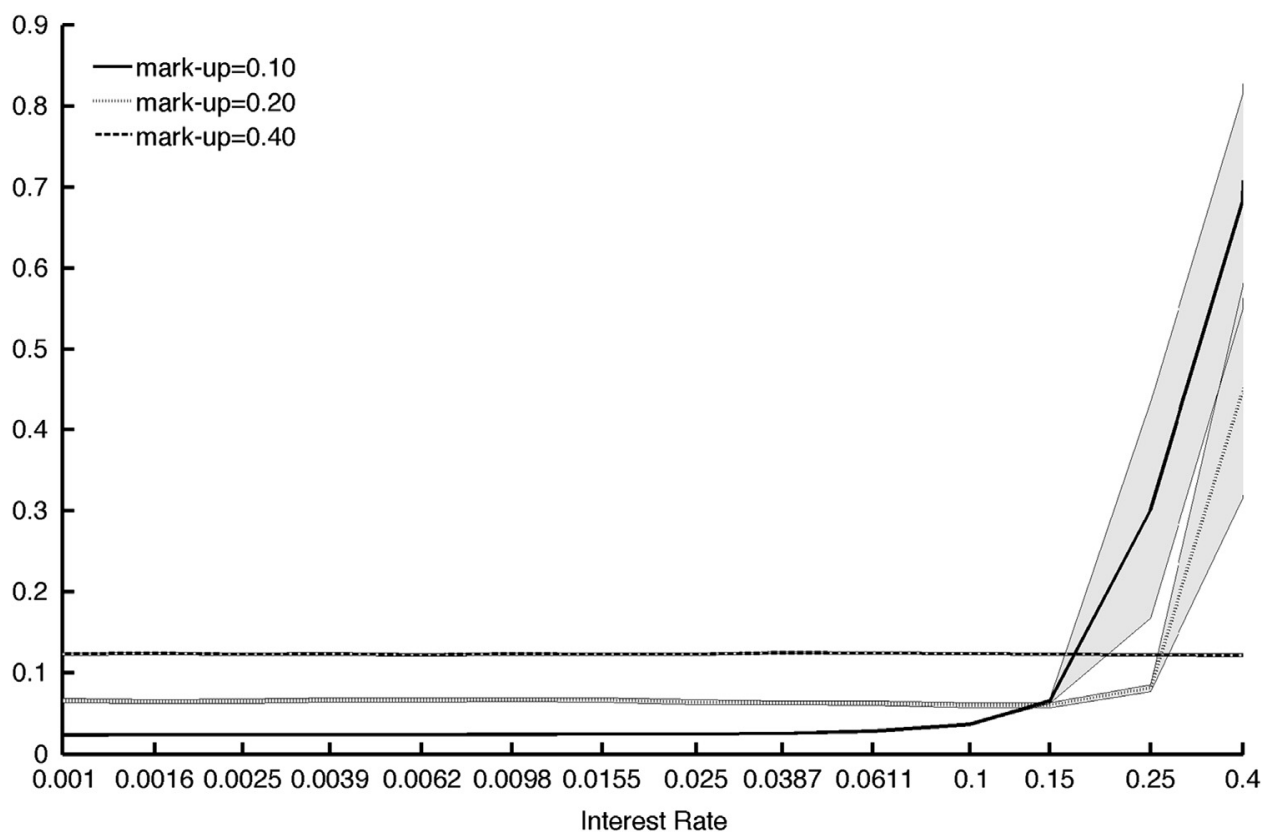

Fig. 17. Standard deviation of GDP growth rate and the interest rate ( $95 \%$ confidence bands in gray).

The general picture is that, when mark-up rates are sufficiently low, changes in interest rates may affect real dynamics in significant but asymmetric ways. In particular high interest rates bring the economy on a low growth trajectory, characterized by wide fluctuations in output and high average unemployment rates. And this dynamic path is strongly correlated to the fall in the frequency of periods the economy spends in full employment (see Fig. 20).

The analysis of bankruptcy rates adds further elements to the picture. First, in line with the results discussed in Section 4.2, average bankruptcy rates decrease with the mark-up rate, for any level of the interest rate (see Fig. 21). Second, bankruptcy rates are not affected by the interest rate for high mark-up rates, while at lower levels of mark-up they steadily increase with the interest rate. It follows that - differently from what observed in fiscal policy experiments - high volatility and incidence of crises are now positively correlated to the bankruptcy rate. 


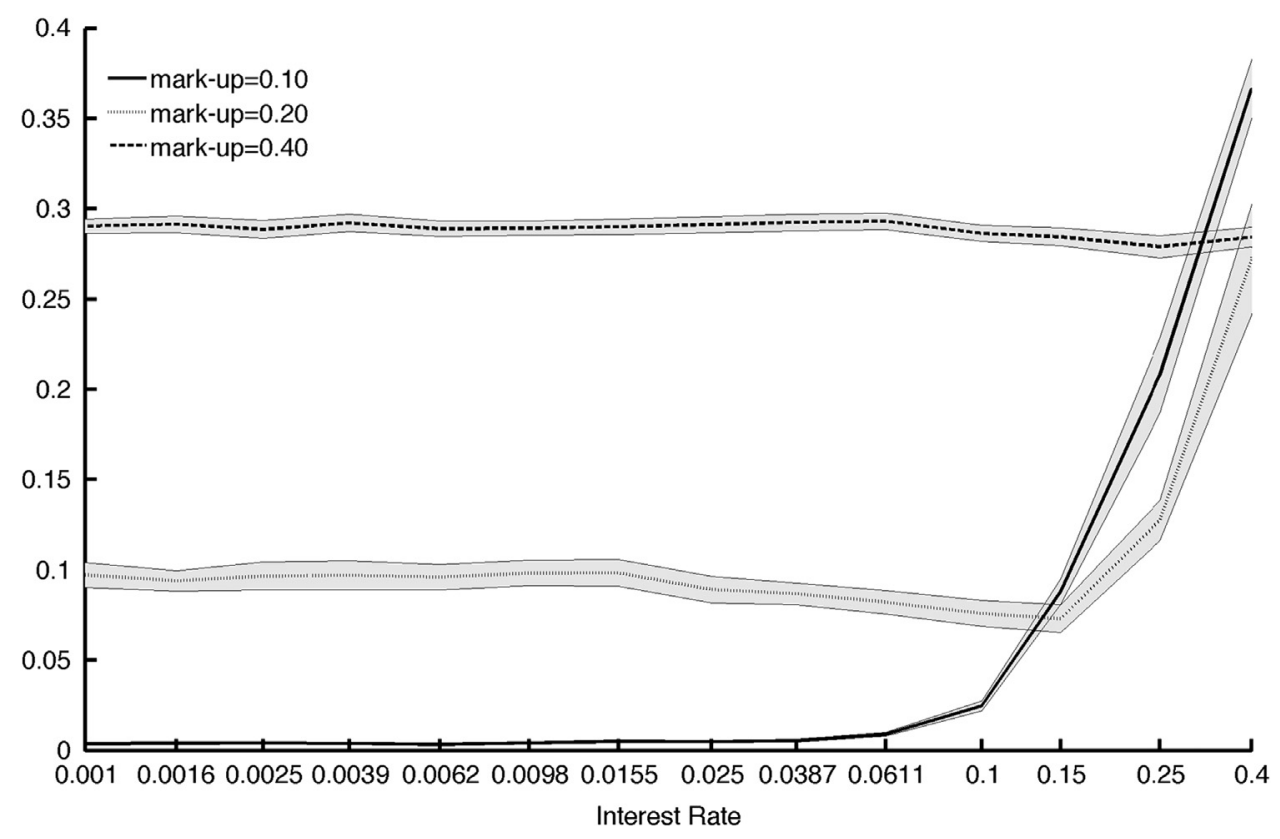

Fig. 18. Likelihood of crises in GDP growth and the interest rate (95\% confidence bands in gray).

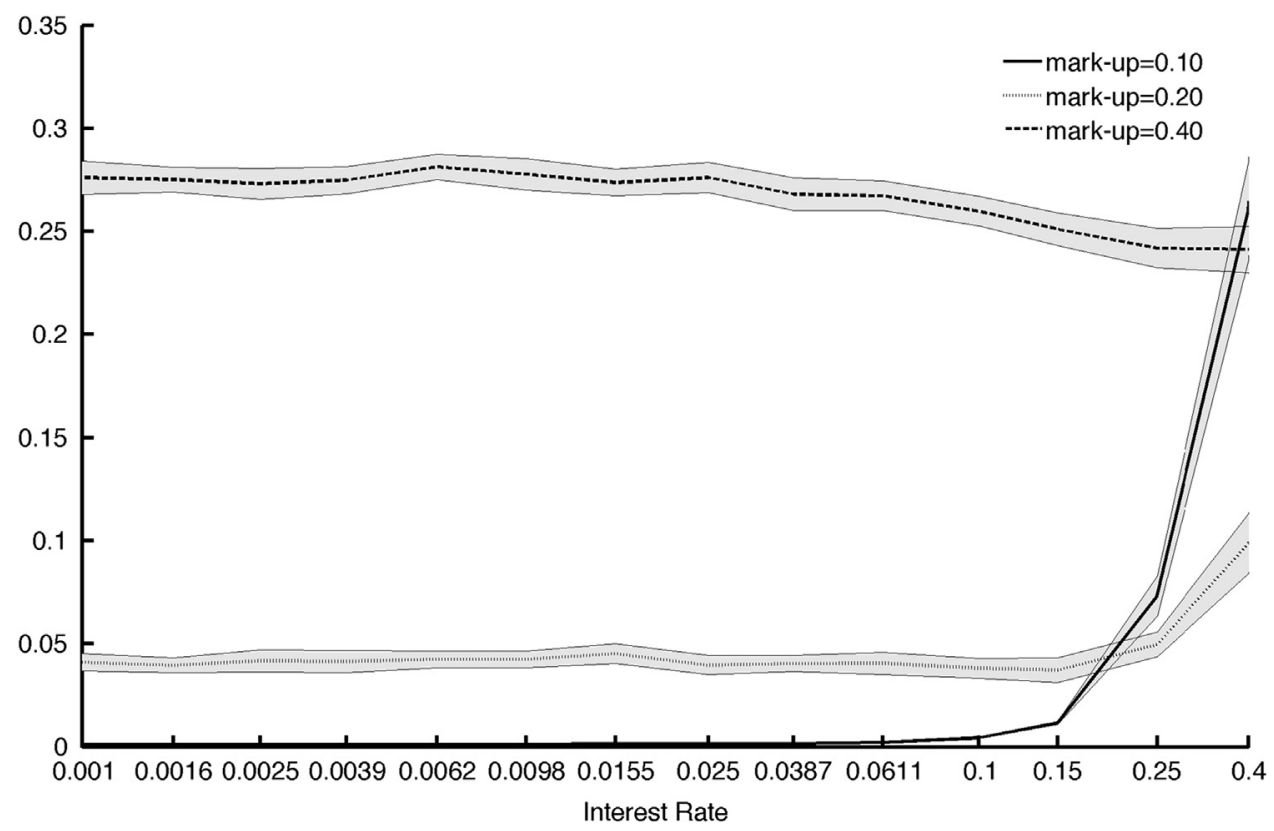

Fig. 19. Unemployment rate and the interest rate (95\% confidence bands in gray).

Credit multipliers: How do the above results change when one varies the maximum credit available in the economy? Fig. 22 shows average GDP growth as a function of the credit multiplier in turn determined by reserve requirements imposed by the Central Bank under different mark-up scenarios. ${ }^{24}$ Similarly to the interest rate experiment, the sensitivity of real variables to changes in the credit multiplier decreases with mark-up rates. It is null in the case of high mark-ups, and it is the highest for low mark-up levels.

\footnotetext{
${ }^{24}$ The following discussion focuses on the effects of credit multipliers. However, results do not change if one changes credit ceilings to single firms instead of the maximum credit supply available in the economy.
} 


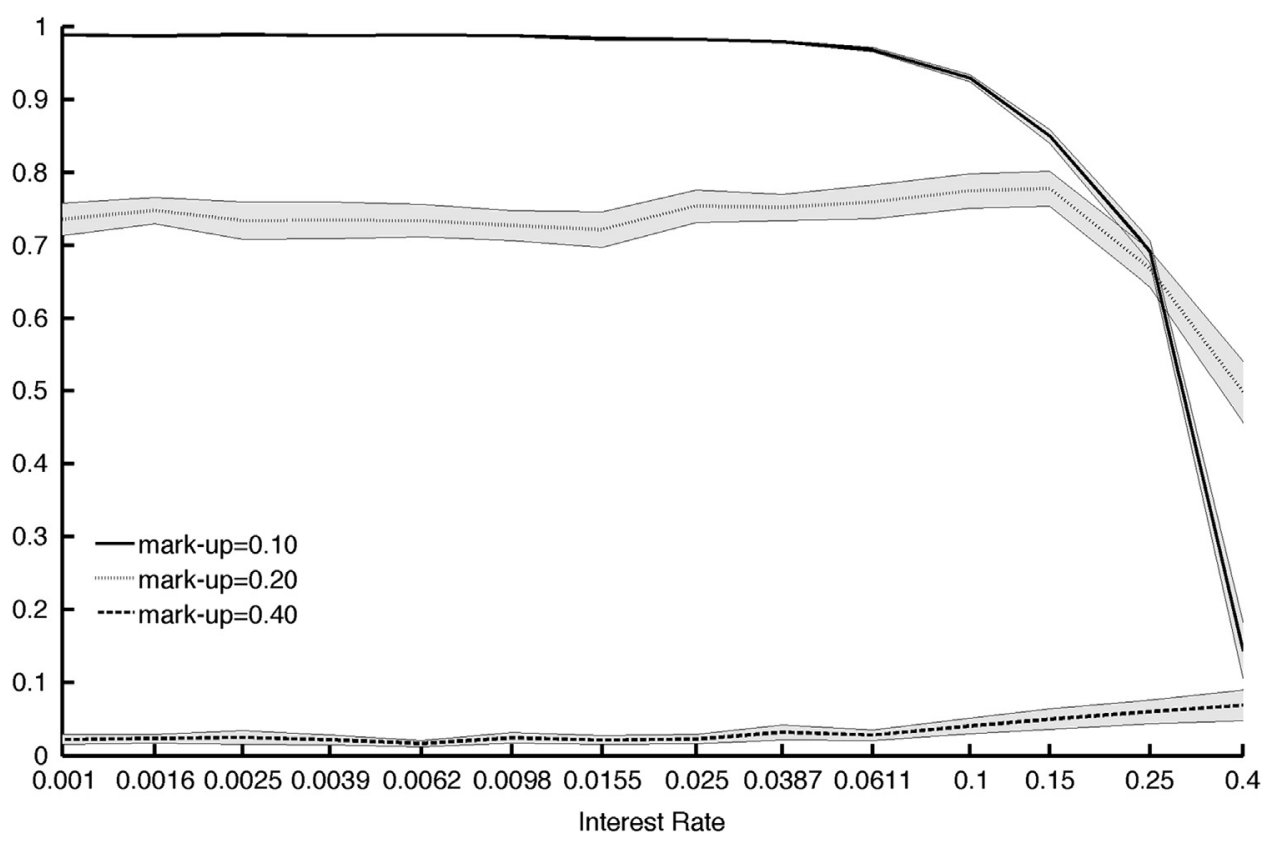

Fig. 20. Frequency of full employment states and the interest rate ( $95 \%$ confidence bands in gray).

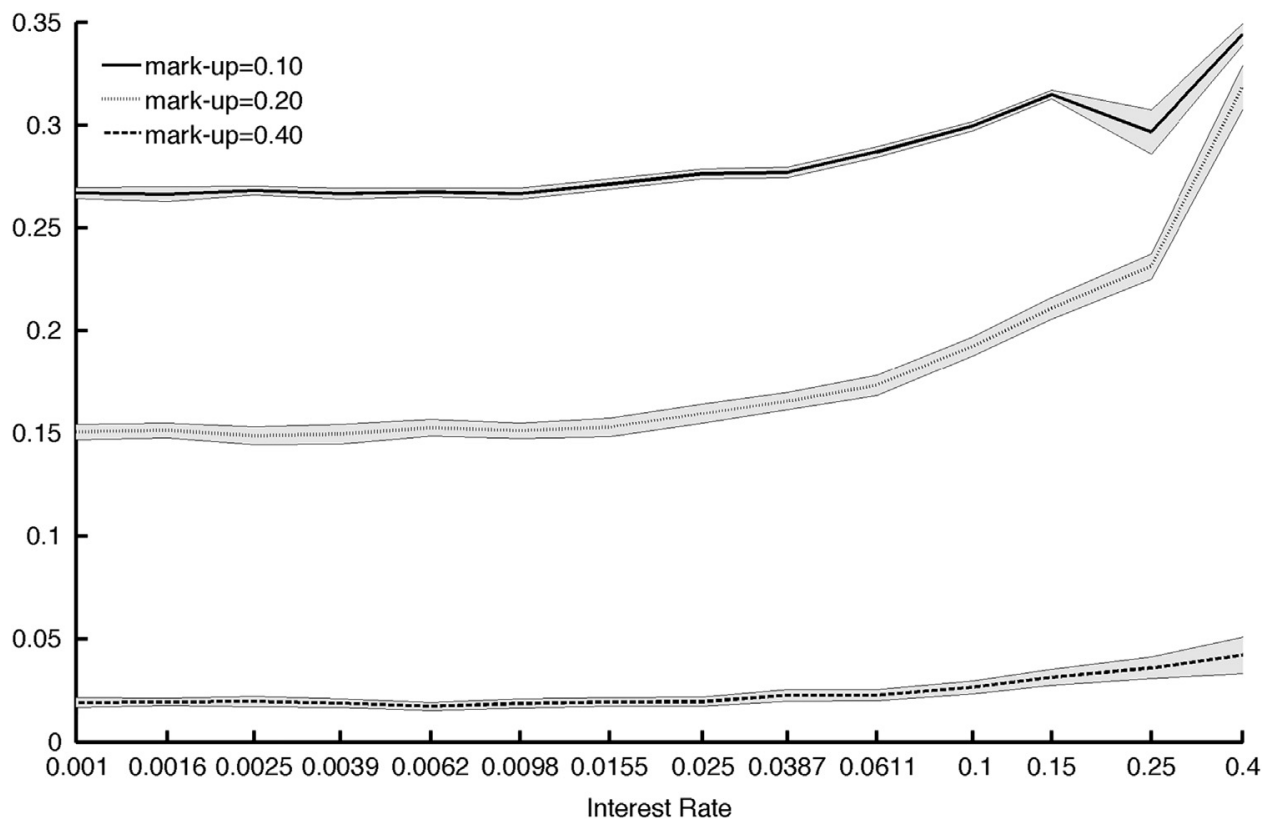

Fig. 21. Bankruptcy rate and the interest rate (95\% confidence bands in gray).

Let us focus on the latter scenario. Fig. 22 shows how the relation between average GDP growth and the credit multiplier is quite asymmetric. Credit "contractions" negatively affect growth. In contrast, expanding total credit above a certain threshold does not lead to significant improvements in growth performance. Also average volatility is significantly affected by changes in the credit multiplier (cf. Fig. 23) and, interestingly, the relation is U-shaped. Volatility is the highest for low and high values of the ratio, while it is minimized for intermediate values. This, we suggest, is due to the effects that this instrument has on the credit supply. Lower levels of the multiplier reduce the availability of loans, forcing firms to rely more on their highly volatile net profits. Less intuitively, at the opposite end, much higher credit multipliers seem to allow firms to excessively finance production and investment, eventually leading to overproduction and overinvestment episodes. 
This U-shaped pattern is even more evident in the analysis of the likelihood of crises (see Fig. 24): under intermediate values, such a likelihood turns out to be strikingly low. Our conjecture is that a "too loose" credit policy neutralizes the selective role of credit allocation and with that allows reckless investments by relatively inefficient firms, thus yielding a sort of boom-and-bust dynamics.

These results uncover another interesting property of the model: raising too much the credit multiplier brings only small contributions to the long-run growth of the economy. At the same time it leads to wider fluctuations and to a higher incidence of crises. In contrast, decreasing too much the multiplier increases both volatility and crises, and also reduces the growth prospects of the economy.

The relationship between credit multiplier and business cycle fluctuations also affects the unemployment rate. Increases in the credit multiplier lead to a dramatic fall of the unemployment rate up to a threshold above which the higher volatility of the economy is reflected also in increasing levels of unemployment (see Figs. 25 and 26 ).

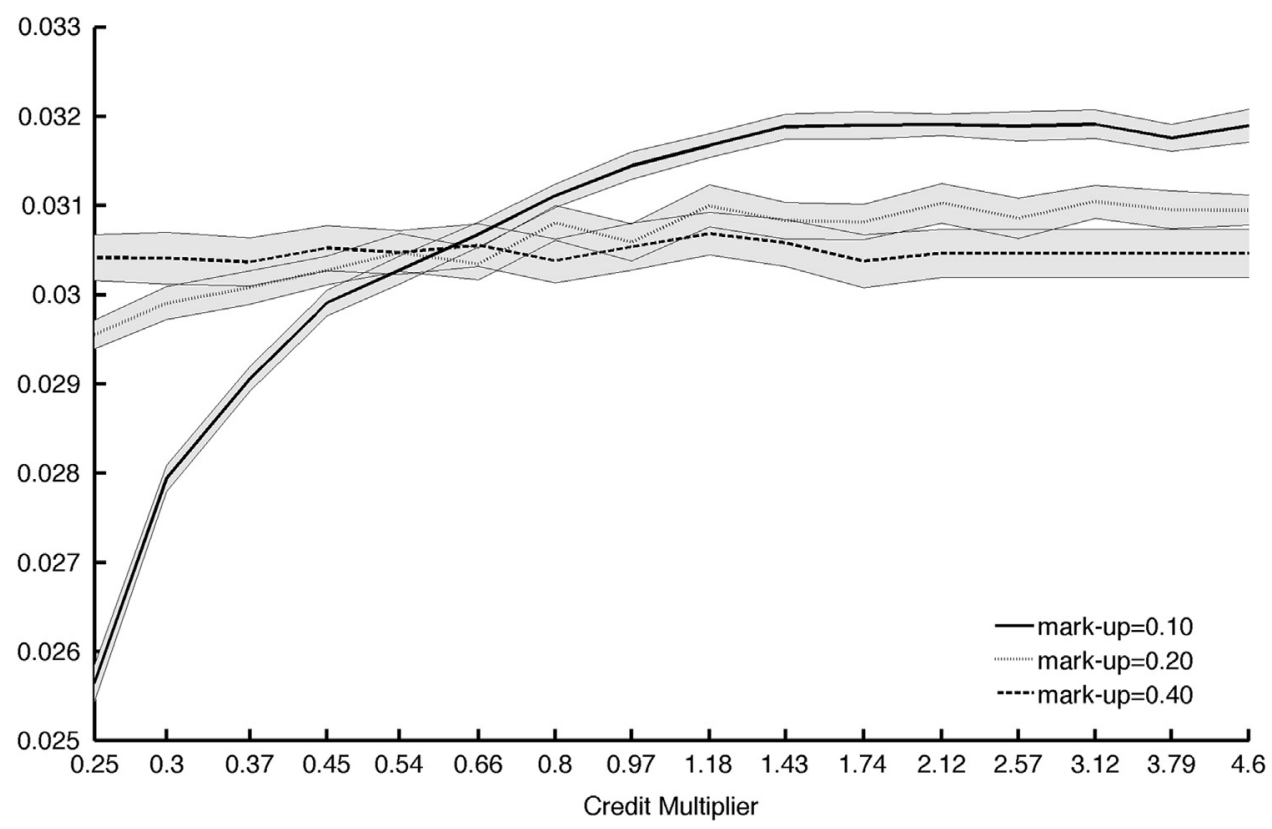

Fig. 22. Average GDP growth and the credit multiplier rate ( $95 \%$ confidence bands in gray).

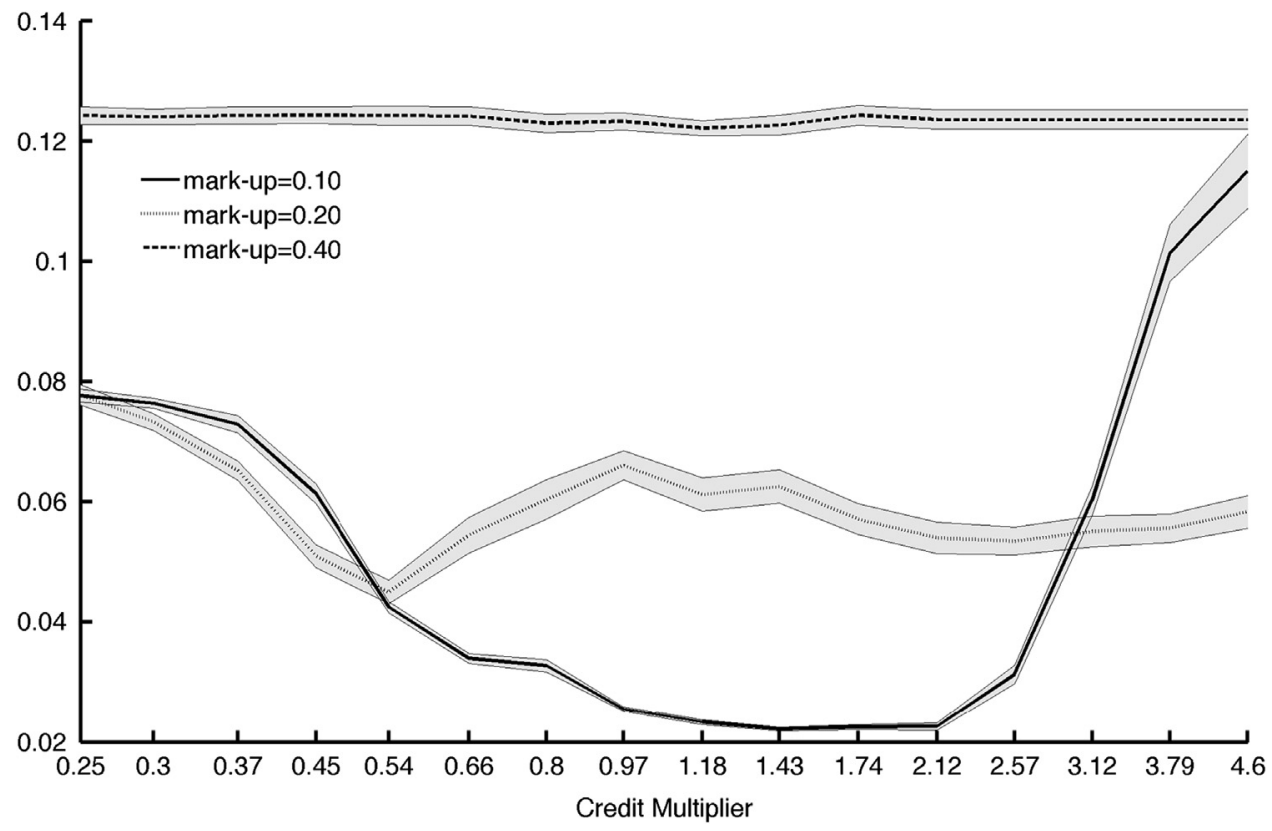

Fig. 23. Standard deviation of GDP growth rate and the credit multiplier rate (95\% confidence bands in gray). 


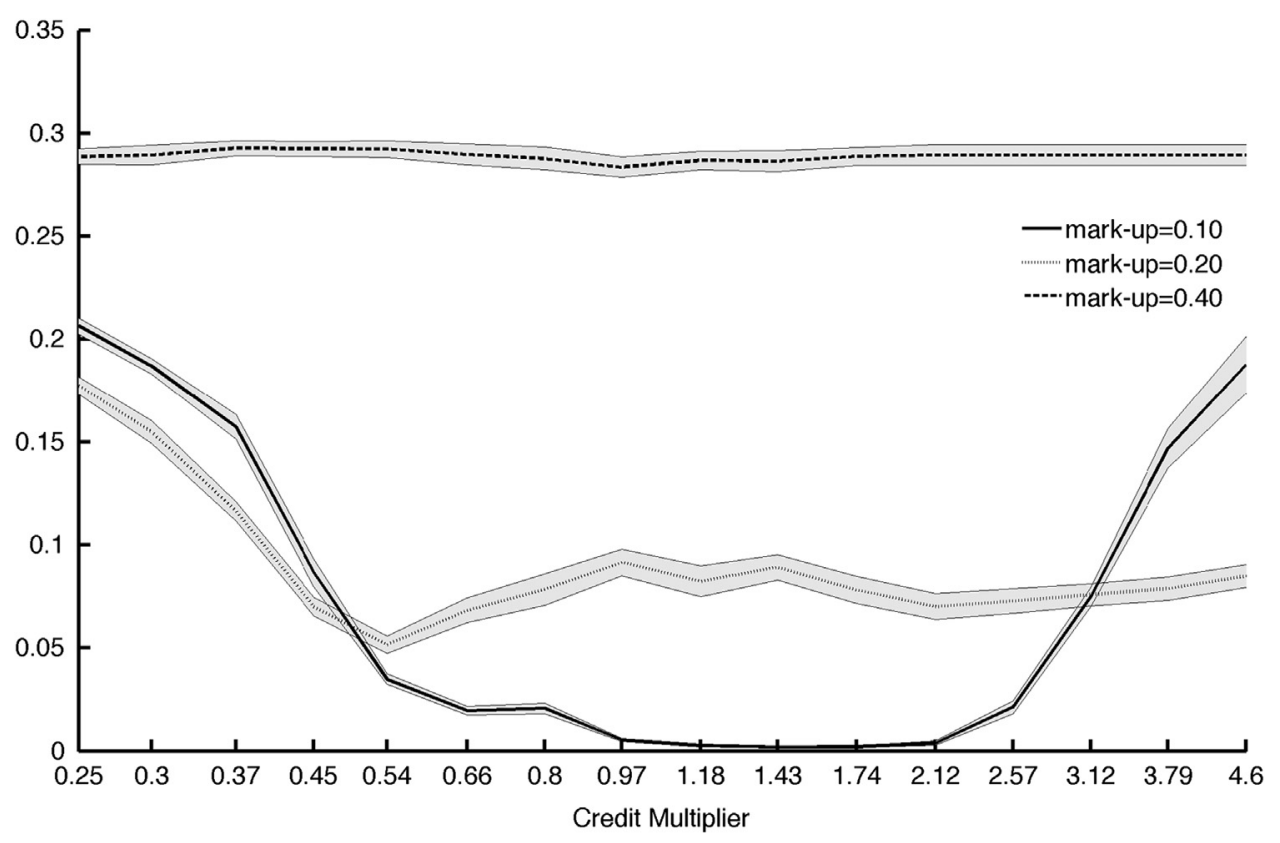

Fig. 24. Likelihood of crises in GDP growth and the credit multiplier rate (95\% confidence bands in gray).

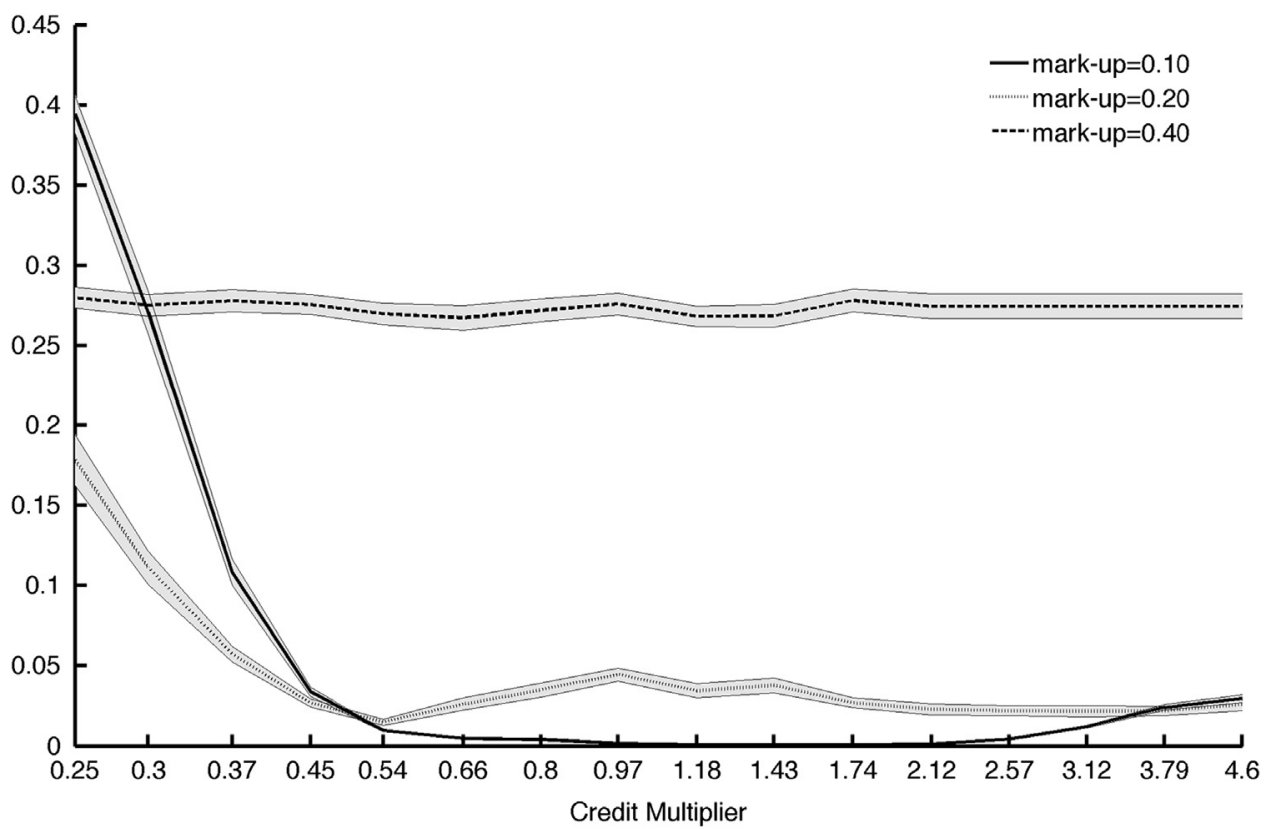

Fig. 25. Unemployment rate and the credit multiplier rate (95\% confidence bands in gray).

Monetary policy effects: a discussion: Let us now summarize the above findings and provide some general interpretations. First, the results show deep interactions between monetary policies and patterns of income distribution. In particular, the lack of sensitivity to changes in monetary policy variables at high mark-up rates is equivalent in our model to the emergence of a sort of liquidity trap. ${ }^{25}$ Increasing mark-ups raise the availability of internal funds to firms. At the same

${ }^{25}$ This type of liquidity trap is of course different from the standard Keynesian one. There agents prefer to keep their funds as money rather than investing them into bonds. Here, instead firms prefer to keep their funds as deposits instead of investing into activities such as production and investment. 


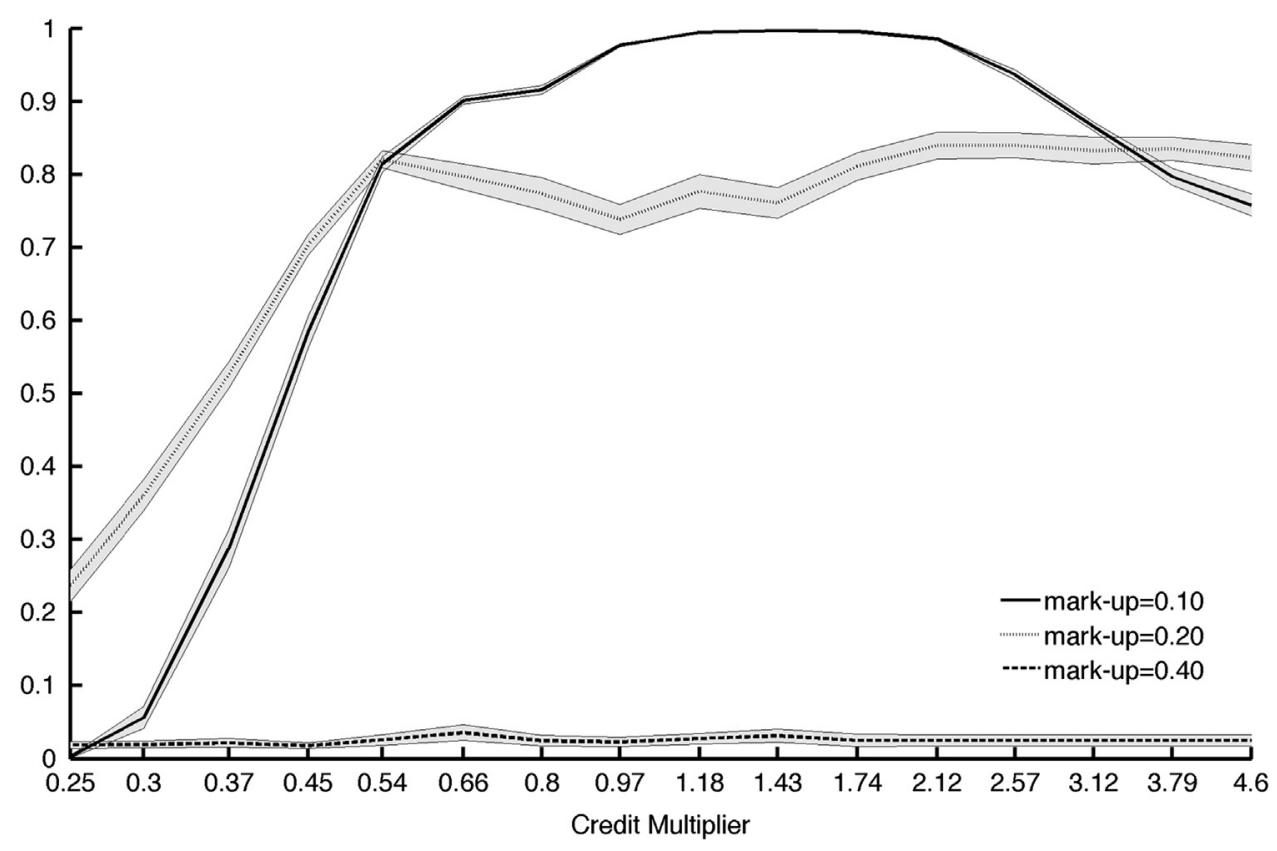

Fig. 26. Frequency of full employment states and the credit multiplier rate (95\% confidence bands in gray).

time, lower wage shares imply lower aggregate consumption propensity. ${ }^{26}$ Via demand expectations, this leads to a lower propensity to invest into the expansion of the productive capacity. When mark-ups are high, the latter mechanism becomes dominant, and therefore firms have plenty of idle funds which are kept as deposits, rather then being invested. In this case, monetary policies can do little to influence the economy, as the low propensity to invest implies also low incentives to raise debt. Second, even when mark-ups are low (and thus the sensitivity to monetary policy interventions is in principle high) there is a system phase of monetary policy ineffectiveness: our results indicate the existence of threshold values below which changes in interest rate or in the credit multiplier have small or no effect on real variables.

Furthermore, the different role played by interest rate vs. credit quantity instruments (credit multipliers) can be explained on the grounds of the different transmission mechanisms through which these instruments operate.

Consider interest rates. First, the level of interest rate affects the real sector through a "balance sheet channel". By impacting on firms' costs, the levels of interest rates determine firms' net cash flows available to finance production and investment plans and symmetrically the requirements of external financing. Second, by determining the net profits of the bank and of the firms, interest rates affect directly (in the former case) and indirectly (in the latter case) the amount of funds redistributed from the real sector to the banking sector. Bank's profits are added to bank reserves, and therefore are not reinvested into credit to firms. It is straightforward that high interest rates imply - ceteris paribus - lower net profits of firms and therefore - via the "bank lending channel" - a lower amount of resources available to finance production and investment expenditures.

Credit multipliers influence too the total level of credit available in the economy. However, by not impacting on firms' costs they do not alter the dynamics of internal funds and the demand for credit of individual firm. This explains also why credit multipliers basically affect the growth of the economy only on the "downside", when the squeeze on credit availability induces a sort of systemic rationing of the economy.

\section{Concluding remarks}

In this paper we have explored the interactions between the financial and real sides of an evolutionary agent-based economy under different mixes of fiscal and monetary policies. After showing the ability of the model to reproduce the main stylized facts concerning credit dynamics at the micro and macro levels, we analyzed the effects of fiscal and monetary policies under different conditions characterizing the distribution of income between wages and profits. Our results emphasize the high interdependence between the effectiveness of macro policies and the patterns of income distribution. In the presence of a high profit margins, redistributive fiscal policies are able to dampen business cycle fluctuations and to keep the economy close to full employment. In line with the result shown in Dosi et al. (2010) we find

\footnotetext{
${ }^{26}$ In our model, to repeat, we make the extreme assumption that all wages are consumed and all profits are either invested or saved. However, our conclusions qualitatively hold as long as, in good Keynesian fashion, the propensity to consume out of profits is lower that that out of wages.
} 
that some fiscal policies are in any case necessary to keep the system away from a stagnant long-term trajectory, even in presence of abundant "Schumpeterian" opportunities of innovation.

Also the effects of monetary policy are highly dependent on income distribution. In particular, monetary policy turns out to be effective only in regimes characterized by low profit-to-GDP ratios. In contrast, high profit shares lead to a form of liquidity trap, wherein firms prefer to keep funds idle instead of investing them into capacity expansion. In such a situation, the ability of monetary policy to stimulate the real sector through the credit channel is totally hampered.

The results of our experiment strongly support the old-fashion Keynesian view of economic policies with their relative emphasis on fiscal ones both as countercyclical instruments and as necessary conditions to keep the economy on a "virtuous" high growth path. Needless to say, if there is some truth in our conclusions they run exactly counter the current European recipes: the recent fiscal austerity programs pursued by EMU countries, if we are right, are likely to worsen the state of the economy, further lowering the rate of growth, and increasing the instability of European economies.

The model can be extended in several directions. First, we deliberately focused on a regime wherein average inflation is zero and the Central Bank interest rate is fixed throughout the experiments. This takes away the effects of further distributive changes induced by different inflation rates. In addition, it allows one to study more neatly the dynamic consequences on output and unemployment of persistent interest rate policies. However, one could easily extend the analysis to a framework in which average inflation can be positive and where the Central Bank adjusts interest rates and credit conditions in the light of some output and inflation targeting (the famous Taylor Rule being one of the possible strategies). This would involve also the introduction of a fullfledged analysis of labor markets (e.g. along the ways followed by Fagiolo et al., 2004; Dawid et al., 2008).

Second, one could extend the present framework introducing heterogeneous banks. This would allow one to study the macroeconomic effects of banking crises and the consequences on output and public finances of different bail-out schemes.

Third, we have assumed a constant number of firms in the model. Although this assumption seems quite reasonable in light of the existing empirical evidence (see the remarks in footnote 8), one could extend the model allowing for a variable number of firms, whose entry depends endogenously on expectations about future market conditions. This extension would allow also to study the effects of monetary and fiscal policies on the entry rate of firms.

Fourth, in this model we assumed that firms follow a mark-up pricing rule. An interesting extension of the paper would consist into testing the implications for aggregate output and price dynamics of alternative pricing rules, (e.g. of the kind discussed in Blinder, 1998).

Finally, the consumption side of the model is highly stylized: workers fully consume their wage. One could easily extend the model allowing for households savings and indebtedness. The latter played an important role in the recent crisis. Indeed, we conjecture, that these modifications are likely to strengthen the main conclusions on the impact of monetary and credit policies discussed in this work.

\section{Acknowledgments}

Thanks, with all usual disclaimers, to the participants to the conference "Le bienfaits de la macroeconomie", organized by Centre Cournot, Paris, December 2010 —in particular Bob Solow; the 16th World Congress of International Economic Association, Beijing, July 2011; the GSDP Workshop, Paris, September 2011; the "DSGE and Beyond" Conference at the National Bank of Poland, Warsaw, September 2011; the POLHIA International Conference "Rethinking Economic Policies in a Landscape of Heterogeneous Agents", Milan, October 2011; and to seminars at the New School University in New York-in particular Willi Semmler; at OFCE, Paris; University Paris 1; the University of Buenos Aires; and the European Central Bank. Thanks also to Tania Treibich, Domenico Delli Gatti, Antoine Mandel, Francesco Saraceno, Jean-Luc Gaffard, Fabrizio Patriarca and Francesco Vona for their comments. The authors gratefully acknowledge the financial support of the Institute for New Economic Thinking (INET) grant \#220, "The Evolutionary Paths Toward the Financial Abyss and the Endogenous Spread of Financial Shocks into the Real Economy" to the Sant'Anna School of Advanced Studies, Pisa. Mauro Napoletano also acknowledges the financial support of the European Commission under the 7th FP POLHIA project (Monetary, Fiscal and Structural Policies with Heterogeneous Agents SSH-CT-2008-225408-POLHIA).

\section{Appendix A. The real-side of the model: a full description}

In this appendix we present the full formal structure of the real side of the model discussed in Section 3. We start with the equations characterizing search processes and the determination of production and prices in the capital-good sector. Next we turn to present the equations related to the determination of production, investment, prices and profits in the consumption-good sector.

\section{A.1. The capital-good industry}

In the capital-good sector there are $F_{1}$ firms denoted by the subscript $i$. The technology of a capital-good firms is defined by the vector $\left(A_{i}^{\tau}, B_{i}^{\tau}\right)$, where the former coefficient is the productivity of the manufactured machine tool in the 
consumption-good industry, the latter coefficient is the efficiency of the production technique employed by the firm, and the positive integer $\tau$ denotes the current technology vintage. Given the monetary wage $w(t)$, the unit cost of production of capital-good firms is

$$
c_{i}(t)=\frac{w(t)}{B_{i}^{\tau}} .
$$

With a fixed mark-up $\left(\mu_{1}>0\right)$ pricing rule, prices $\left(p_{i}(t)\right)$ are defined as

$$
p_{i}(t)=\left(1+\mu_{1}\right) c_{i}(t)
$$

The unit labor cost of production entailed by a machine in the consumption-good sector is

$$
c\left(A_{i}^{\tau}, t\right)=\frac{w(t)}{A_{i}^{\tau}} .
$$

Capital-good firms invest in R\&D a fraction of their past sales $\left(S_{i}\right)$

$$
R D_{i}(t)=v S_{i}(t-1)
$$

with $0<v<1$. R\&D expenditures are used to hire researchers paying the market wage $w(t)$. Firms split their R\&D efforts between innovation (IN) and imitation (IM) according to the parameter $\xi \in[0,1]$

$$
\begin{aligned}
& I N_{i}(t)=\xi R D_{i}(t), \\
& I M_{i}(t)=(1-\xi) R D_{i}(t) .
\end{aligned}
$$

We model innovation as a two-step process. The first step determines whether a firm successfully innovates or not through a draw from a Bernoulli distribution, whose parameter $\theta_{i}^{i n}(t)$ is given by

$$
\theta_{i}^{i n}(t)=1-e^{-\zeta_{1} I N_{i}(t)}
$$

with $0<\zeta_{1} \leq 1$. If a firm innovates, it gets the new technology $\left(A_{i}^{i n}, B_{i}^{i n}\right)$ according to

$$
\begin{aligned}
& A_{i}^{i n}(t)=A_{i}(t)\left(1+x_{i}^{A}(t)\right), \\
& B_{i}^{i n}(t)=B_{i}(t)\left(1+x_{i}^{B}(t)\right),
\end{aligned}
$$

where $x_{i}^{A}$ and $x_{i}^{B}$ are two independent draws from a Beta $\left(\alpha_{1}, \beta_{1}\right)$ over the support $\left[\underline{x}_{1}, \bar{x}_{1}\right]$ with $\underline{x}_{1}$ belonging to the interval $[-1,0]$ and $\bar{x}_{1}$ to $[0,1] .{ }^{27}$ Imitation follows a two steps procedure as well. The set of successfully imitating firms is formed sampling from a Bernoulli $\left(\theta_{i}^{i m}(t)\right)$

$$
\theta_{i}^{i m}(t)=1-e^{-\zeta_{2} I M_{i}(t)}
$$

with $0<\zeta_{2} \leq 1$. Firms accessing the second stage are able to copy the technology of one competitor $\left(A_{i}^{i m}, B_{i}^{i m}\right)$. We assume that firms are more likely to imitate competitors with similar technologies. For that, we use an Euclidean metrics to compute the technological distance between every pair of firms to weight imitation probabilities.

Firms that successfully innovate or imitate must decide which type of machine is put on production. Knowing that consumption-good firms invest following a payback period routine (see below), capital-good firms select the machine to produce according to the rule:

$$
\min \left[p_{i}^{h}(t)+b c^{h}\left(A_{i}^{h}, t\right)\right], \quad h=\tau, i n, i m,
$$

where $b$ is a positive payback period parameter (cf. Eq. (21) below). Capital-good firms send then a "brochure" with the price and the productivity of their machines to both their historical $\left(H C_{i}\right)$ and a random sample of potential new customers $\left(N C_{i}\right)$. The size of the latter is proportional to $H C_{i}$ (i.e. $N C_{i}(t)=\gamma H C_{i}(t)$, with $\gamma \in(0,1)$ ).

\section{A.2. The consumption-good industry}

The consumption-good sector is composed of $F_{2}$ firms labelled by the subscript $j$. Consumption-good firms plan their production $\left(Q_{j}\right)$ following the simplest adaptive demand expectations $\left(D_{j}^{e}\right)$ :

$$
D_{j}^{e}(t)=D_{j}(t-1)
$$

where $D_{j}(t-1)$ is the past demand actually faced by firm $j$. The desired level of production $\left(Q_{j}^{d}\right)$ is computed adding the desired inventories $\left(N_{j}^{d}\right)$ and the actual stock of inventories $\left(N_{j}\right)$ to the expected demand:

$$
Q_{j}^{d}(t)=D_{j}^{e}(t)+N_{j}^{d}(t)-N_{j}(t-1)
$$

\footnotetext{
${ }^{27}$ We choose the Beta distribution because of its flexibility, able in particular to capture, according to the parameterization, poorer or richer opportunities to make long "jumps" in the productivity space.
} 
with $N_{j}^{d}(t)=\imath D_{j}^{e}(t), l \in[0,1]$. Given the desired level of production and the desired rate of capacity utilization $\left(c u^{d}\right)$, firms compute their desired capital stock $\left(K_{j}^{d}\right)$

$$
K_{j}^{d}(t)=\frac{Q_{j}^{d}(t)}{c u^{d}} .
$$

If the desired capital stock is higher than the current capital stock, firms invest $\left(E I_{j}^{d}\right)$ in order to increase their capital $\operatorname{stock}^{28}\left(K_{j}\right)$

$$
E I_{j}^{d}(t)=K_{j}^{d}(t)-K_{j}(t)
$$

We define as $\Xi_{j}(t)$ the set of all vintages of machine tools belonging to firm $j$ at time $t$. Moreover, if we measure machines in terms of their production capacity (normalized to one), the capital stock is defined as:

$$
K_{j}(t)=\sum_{A_{i}^{\tau} \in \Xi_{j}(t)} g_{j}\left(A_{i}^{\tau}, t\right)
$$

where $g_{j}\left(A_{i}^{\tau}, t\right)$ is the absolute frequency of machine $A_{i}^{\tau}$.

Firms scrap machines according to a payback period routine. More specifically, firm $j$ replaces machine $A_{i}^{\tau} \in \Xi_{j}(t)$ according to its technology obsolescence as well as to the price of new machines:

$$
R S_{j}(t)=\left\{A_{i}^{\tau} \in \Xi_{j}(t): \frac{p^{*}(t)}{c\left(A_{i, \tau}, t\right)-c^{*}(t)} \leq b\right\},
$$

where $p^{*}$ and $c^{*}$ are the price and unit cost of production of new machines. Firms compute their replacement investment summing up the machine-tools satisfying Eq. (21). Moreover, they also scrap the machines older than $\eta$ periods ( $\eta$ positive integer). Summing up expansion and replacement investment one gets the gross investment of each firm $\left(I_{j}\right)$.

Given the "brochures" received by (a subset of) capital-good firms, consumption-good firms send their investment order to the supplier with the lowest price and unit cost of production (i.e. $\left.p_{i}(t)+b c\left(A_{i}^{\tau}, t\right)\right)$. The ordered machines are going to be delivered at the end of the period. Consumption-good firms compute average productivity $\left(\pi_{j}\right)$ and unit cost of production $\left(c_{j}\right)$

$$
\begin{aligned}
\pi_{j}(t) & =\sum_{A_{i}^{\tau} \in \Xi_{j}(t)} A_{i}^{\tau} \frac{g_{j}\left(A_{i}^{\tau}, t\right)}{K_{j}(t)}, \\
c_{j}(t) & =\frac{w(t)}{\pi_{j}(t)} .
\end{aligned}
$$

Prices are set applying a variable markup $\left(\mu_{j}\right.$, see Eq. (3)) on unit costs of production

$$
p_{j}(t)=\left(1+\mu_{j}(t)\right) c_{j}(t) .
$$

The competitiveness $\left(E_{j}\right)$ of consumption-good firms depends both on price and on the past level of unfilled demand $\left(l_{j}\right)$

$$
E_{j}(t)=-\omega_{1} p_{j}(t)-\omega_{2} l_{j}(t),
$$

where $\omega_{1,2}$ are positive parameters. Weighting the competitiveness of each consumption-good firms by its past market share $\left(f_{j}\right)$, one can compute the average competitiveness of the consumption-good sector

$$
\bar{E}(t)=\sum_{j=1}^{F_{2}} E_{j}(t) f_{j}(t-1) .
$$

Firms' market shares evolve according to a replicator dynamics

$$
f_{j}(t)=f_{j}(t-1)\left(1+\chi \frac{E_{j}(t)-\bar{E}(t)}{\bar{E}(t)}\right),
$$

with $\chi>0$. Aggregate consumption $C$ is allocated to consumption-good firms proportionally to their market shares

$$
D_{j}(t)=f_{j}(t) C(t) \text {. }
$$

The profits $\left(\Pi_{j}\right)$ of each consumption-good firm read as

$$
\Pi_{j}(t)=S_{j}(t)-P C_{j}(t)-r D e b_{j}(t),
$$

with $S_{j}(t)=p_{j}(t) D_{j}(t), P C_{j}(t)=c_{j}(t) Q_{j}(t)$ and $D e b_{j}$ denotes the stock of debt. The investment choices of consumption-good firms and their profits determine the evolution of their stock of liquid assets $\left(N W_{j}\right)$

$$
N W_{j}(t)=N W_{j}(t-1)+\Pi_{j}(t)-c I_{j},
$$

\footnotetext{
${ }^{28}$ We assume that in any given period firm capital growth rates cannot exceed a fixed maximum threshold consistent with the maximum capital growth rates found in the empirical literature on firm investment patterns (e.g. Doms and Dunne, 1998).
} 
Table A1

Balance sheet of a consumption-good firm.

\begin{tabular}{ll}
\hline Assets & Liabilities \\
\hline Capital stock $\left(K_{j}\right)$ & Debt $\left(\operatorname{Deb}_{j}\right)$ \\
Inventories $\left(N_{j}\right)$ & Equity $\left(E Q_{j}\right)$ \\
Stock of liquid asset $\left(N W_{j}\right)$ & \\
\hline
\end{tabular}

where $c I_{j}$ is the amount of internal funds employed by firm $j$ (with $c I_{j}(t) \leq N W_{j}(t-1)$ ). The balance sheet of a consumption-good firm is reported in Table A1.

The monetary/credit side of the model is described in the text.

\section{Appendix B. Simulations and "benchmark" system parameters}

\begin{tabular}{|c|c|c|}
\hline Description & Symbol & Value \\
\hline Number of firms in capital-good industry & $F_{1}$ & 50 \\
\hline Number of firms in consumption-good industry & $F_{2}$ & 200 \\
\hline$R \& D$ investment propensity & $v$ & 0.04 \\
\hline$R \& D$ allocation to innovative search & $\xi$ & 0.50 \\
\hline Firm search capabilities parameters & $\zeta_{1,2}$ & 0.30 \\
\hline Beta distribution parameters (innovation process) & $\left(\alpha_{1}, \beta_{1}\right)$ & $(3,3)$ \\
\hline Beta distribution support (innovation process) & {$\left[\underline{x}_{1}, \bar{x}_{1}\right]$} & {$[-0.15,0.15]$} \\
\hline New-customer sample parameter & $\gamma$ & 0.50 \\
\hline Desired inventories & $i$ & 0.10 \\
\hline Payback period & $b$ & 3 \\
\hline "Physical" scrapping age & $\eta$ & 20 \\
\hline Capital-good firm mark-up rate & $\mu_{1}$ & 0.04 \\
\hline Consumption-good firm initial mark-up & $\bar{\mu}(0)$ & 0.20 \\
\hline Coefficient in the consumption-good firm mark-up rule & $v$ & 0.01 \\
\hline Competitiveness weights & $\omega_{1,2}$ & 1 \\
\hline Replicator dynamics coefficient & $\chi$ & 1 \\
\hline Wage setting $\triangle \overline{A B}$ weight & $\psi_{1}$ & 1 \\
\hline Wage setting $\Delta c p i$ weight & $\psi_{2}$ & 0 \\
\hline Wage setting $\Delta U$ weight & $\psi_{3}$ & 0 \\
\hline Tax rate & $\operatorname{tr}$ & 0.10 \\
\hline Unemployment subsidy rate & $\varphi$ & 0.40 \\
\hline Loan-to-value ratio & $\lambda$ & 2 \\
\hline Credit multiplier & $k$ & 2 \\
\hline Baseline interest rate & $r$ & 0.025 \\
\hline Bank mark-up coefficient & $\psi_{L}$ & 0.50 \\
\hline Bank mark-down coefficient & $\psi_{D}$ & 1 \\
\hline
\end{tabular}

\section{References}

Akerlof, G.A., 2002. Behavioral macroeconomics and macroeconomic behavior. American Economic Review 92, 411-433.

Ashraf, Q., Gershman, B., Howitt, P., 2011. Banks, Market Organization, and Macroeconomic Performance: An Agent-Based Computational Analysis. Working Paper 17102. NBER.

Atkinson, A.B., Piketty, T. (Eds.), 2010. Top Incomes: A Global Perspective, Oxford University Press.

Bartelsman, E., Doms, M., 2000. Understanding productivity: lessons from longitudinal microdata. Journal of Economic Literature 38, 569-594.

Bartelsman, E., Scarpetta, S., Schivardi, F., 2005. Comparative analysis of firm demographics and survival: evidence from micro-level sources in OECD countries. Industrial and Corporate Change 14, 365-391.

Bernanke, B., Gertler, M., Gilchrist, S., 1999. The financial accelerator in a quantitative business cycle framework. In: Taylor, J., Woodford, M. (Eds.), Handbook of Macroeconomics, Elsevier Science, Amsterdam.

Bernanke, B.S., Blinder, A.S., 1988. Credit, money, and aggregate demand. American Economic Review 782, $435-439$.

Bernanke, B.S., Blinder, A.S., 1992. The federal funds rate and the channels of monetary transmission. American Economic Review 824, 901-921.

Black, L., Rosen, R., 2011. The Effect of Monetary Policy on the Availability of Credit: How the Credit Channel Works. Working Paper 2007-13. FRB of Chicago.

Blinder, A., 1998. Asking About Prices: A New Approach to Understanding Price Stickiness. Russell Sage Foundation Publications.

Charpe, M., Flaschel, P., Proano, C., Semmler, W., 2009. Overconsumption, credit rationing and bailout monetary policy: a Minskyan perspective. European Journal of Economics and Economic Policies 62, 247-270.

Chiarella, Carl, Di Guilmi, Corrado, 2011. The financial instability hypothesis: a stochastic microfoundation framework. Journal of Economic Dynamics and Control 35 (8), 1151-1171, Elsevier. 
Chiarella, C., Flaschel, P., 2001. The macro dynamics of debt deflation. In: Bellofiore, R., Ferri, P. (Eds.), Financial Fragility and Financial Investment in the Capitalist Economy. The Economic Legacy of Hyman Minsky, vol. II., Edward Elgar, Northampton, MA, pp. 133-184.

Christiano, L.G., Eichenbaum, M., Evans, C.L., 2005. Nominal rigidities and the dynamic effects of a shock to monetary policy. Journal of Political Economy $113,1-45$.

Ciarli, T., Lorentz, A., Savona, M., Valente, M., 2010. The effect of consumption and production structure on growth and distribution. A micro to macro model. Metroeconomica 611, 180-218.

Ciccarelli, M., Maddaloni, A., Peydró, J.-L., 2010. Trusting the Bankers: A New Look at the Credit Channel of Monetary Policy. Working Paper Series 1228. European Central Bank.

Cincotti, S., Raberto, M., Teglio, A., 2010. Credit money and macroeconomic instability in the agent-based model and simulator eurace. Economics: The Open-Access, Open-Assessment E-Journal, 42010-42026.

Claessens, S., Kose, M., Terrones, M., 2009. What happens during recessions, crunches and busts? Economic Policy 2460, 653-700.

Dawid, H., Gemkow, S., Harting, P., Kabus, K., Wersching, K., Neugart, M., 2008. Skills, innovation, and growth: an agent-based policy analysis. Journal of Economics and Statistics $2282+3,251-275$.

Dawid, H., Gemkow, S., van der Hoog, S., Neugart, M., 2011. The Eurace@Unibi Model: An Agent-based Macroeconomic Model for Economic Policy Analysis. Working Paper. Universität Bielefeld.

Del Boca, A., Galeotti, M., Himmelberg, C.P., Rota, P., 2008. Investment and time to plan and build: a comparison of structures vs. equipment in a panel of italian firms. Journal of the European Economic Association 6, 864-889.

Delli Gatti, D., Desiderio, S., Gaffeo, E., Cirillo, P., Gallegati, M., 2011. Macroeconomics from the Bottom-up. Springer, Milan.

Delli Gatti, D., Di Guilmi, C., Gaffeo, E., Giulioni, G., Gallegati, M., Palestrini, A., 2005. A new approach to business fluctuations: heterogeneous interacting agents, scaling laws and financial fragility. Journal of Economic Behavior and Organization 56, 489-512.

Delli Gatti, D., Gallegati, M., Greenwald, B., Russo, A., Stiglitz, J., 2010. The financial accelerator in an evolving credit network. Journal of Economic Dynamics \& Control 34, 1627-1650.

Di Guilmi, C., Gallegati, M., Ormerod, P., 2004. Scaling invariant distributions of firms' exit in OECD countries. Physica A: Statistical Mechanics and its Applications 3341, 267-273.

Doms, M., Dunne, T., 1998. Capital adjustment patterns in manufacturing plants. Review Economic Dynamics 1, 409-429.

Dosi, G., 2007. Statistical regularities in the evolution of industries. A guide through some evidence and challenges for the theory. In: Malerba, F., Brusoni, S. (Eds.), Perspectives on Innovation, Cambridge University Press, Cambridge, MA.

Dosi, G., 2011. Economic Coordination and Dynamics: Some Elements of an Alternative "Evolutionary" Paradigm. Technical Report. Institute for New Economic Thinking.

Dosi, G., Fagiolo, G., Roventini, A., 2006. An evolutionary model of endogenous business cycles. Computational Economics 27, 3-34.

Dosi, G., Fagiolo, G., Roventini, A., 2010. Schumpeter meeting Keynes: a policy-friendly model of endogenous growth and business cycles. Journal of Economic Dynamics \& Control 34, 1748-1767.

Eisner, R., 1972. Components of capital expenditures: replacement and modernization versus expansion. The Review of Economics and Statistics 54, 297-305.

Fabiani, S., Druant, M., Hernando, I., Kwapil, C., Landau, B., Loupias, C., Martins, F., Mathä, T., Sabbatini, R., Stahl, H., Stokman, A., 2006. What firms' surveys tell us about price-setting behavior in the euro area. International Journal of Central Banking 2, 3-47.

Fagiolo, G., Dosi, G., Gabriele, R., 2004. Matching, bargaining, and wage setting in an evolutionary model of labor market and output dynamics. Advances in Complex Systems 14, 237-273.

Fagiolo, G., Roventini, A., 2012. Macroeconomic policy in DSGE and agent-based models. Revue de l'OFCE. 124, 67-116.

Fazzari, S., Ferri, P., Greenberg, E., 2008. Cash flow, investment, and Keynes-Minsky cycles. Journal of Economic Behavior Organization 653, 555-572.

Fazzari, S.M., Hubbard, G.R., Petersen, B.C., 1988. Financing constraints and corporate investment. Brookings Papers on Economic Activity 1, 141-195.

Feldstein, M., Foot, D., 1971. The other half of gross investment: replacement and modernization expenditures. The Review of Economics and Statistics 53 , 49-58.

Fisher, I., 1933. The debt-deflation theory of great depressions. Econometrica 1, 337-357.

Fitoussi, J., Saraceno, F., 2010. Inequality and Macroeconomic Performance. Document de Travail 2010-13. OFCE.

Fujiwara, Y., 2004. Zipf law in firms bankruptcy. Physica A: Statistical and Theoretical Physics 3371 (2), 219-230.

Gai, P., Haldane, A., Kapadia, S., 2011. Complexity, concentration and contagion. Journal of Monetary Economics 58, 453-470.

Gertler, M., 1988. Financial structure and aggregate economic activity: an overview. Journal of Money, Credit and Banking 203, 559-588.

Gertler, M., Gilchrist, S., 1994. Monetary policy, business cycles, and the behavior of small manufacturing firms. The Quarterly Journal of Economics 1092 309-340.

Gertler, M., Kiyotaki, N., 2010. Financial intermediation and credit policy in business cycle analysis. In: Friedman, B.M., Woodford, M. (Eds.), Handbook of Monetary Economics, North Holland, Amsterdam.

Goolsbee, Austan., 1998. The business cycle, financial performance, and the retirement of capital goods, Review of Economic Dynamics, Elsevier for the Society for Economic Dynamics, 1 (2), 474-496.

Greenwald, B., Stiglitz, J., 1993. Financial market imperfections and business cycles. Quarterly Journal of Economics 108, 77-114.

Gurley, J., Shaw, E., 1955. Financial aspects of economic development. American Economic Review 45, 515-538.

Hubbard, G.R., 1995. Is there a "credit channel" for monetary policy? Federal Reserve of St. Louis Review 5, 1.

Hubbard, G.R., 1998. Capital-market imperfections and investment. Journal of Economic Literature 36, 193-225.

Kashyap, A.K., Stein, J.C., 2000. What do a million observations on banks say about the transmission of monetary policy? American Economic Review 903 407-428.

Kashyap, A.K., Stein, J.C., Wilcox, D.W., 1993. Monetary policy and credit conditions: evidence from the composition of external finance. American Economic Review. 831, 78-98.

Keen, S., 1995. Finance and economic breakdown: modeling minsky's "financial instability hypothesis". Journal of Post Keynesian Economics 174 607-635.

Keynes, J.M., 1936. The General Theory of Employment, Interest, and Money. Prometheus Books, New York.

Kindleberger, C., 1978. Manias, Panics, and Crashes. Basic Books, New York.

Kirman, A.P., 1992. Whom or what does the representative individual represent? Journal of Economic Perspectives 6, 117-136.

Kirman, A.P., 2010. The economic crisis is a crisis for economic theory. CESifo Economic Studies 56, 498-535.

Kiyotaki, N., Moore, J., 1997. Credit cycles. Journal of Political Economy 1052, 211-248.

Krugman, P., 2011. Mr. Keynes and the "Moderns". In: Prepared for the Cambridge Conference Commemorating the 75th Anniversary of the Publication of The General Theory of Employment, Interest, and Money.

Kumhof, M., Rancière, R., 2010. Inequality, Leverage and Crisis. Working Paper WP/10/268. IMF.

Leary, M., 2009. Bank loan supply, lender choice, and corporate capital structure. The Journal of Finance 643, 1143-1185.

LeBaron, B., Tesfatsion, L., 2008. Modeling macroeconomies as open-ended dynamic systems of interacting agents. American Economic Review 98, $246-250$.

Lown, C., Morgan, D., 2006. The credit cycle and the business cycle: new findings using the loan officer opinion survey. Journal of Money, Credit, and Banking 386, 1575-1597.

Malerba, F., Orsenigo, L., 1996. The dynamics and evolution of industries. Industrial and Corporate Change 51, 51-87.

Minsky, H., 1975. John Maynard Keynes. Macmillan, London, pp. 1106-108. 
Minsky, H., 1977. The financial instability hypothesis: an interpretation of Keynes and an alternative to standard theory. Challenge $201,20-27$.

Minsky, H., 1982. Can It Happen Again?. M.E. Sharpe, New York.

Minsky, H., 1986. Stabilizing an Unstable Economy. Yale University Press, New Haven.

Mishkin, F., 1995. Symposium on the monetary transmission mechanism. The Journal of Economic Perspectives 94, 3-10.

Modigliani, F., Miller, M., 1958. The cost of capital, corporation finance and the theory of investment. American Economic Review $48,261-297$.

Napoletano, M., Dosi, G., Fagiolo, G., Roventini, A., 2012. Wage formation, investment behavior and growth regimes: an agent-based analysis. Revue de l'OFCE 124, 235-261.

Napoletano, M., Roventini, A., Sapio, S., 2006. Are business cycles all alike? A bandpass filter analysis of the Italian and US cycles. Rivista Italiana degli Economisti 1, 87-118.

Nelson, R.R., Winter, S.G., 1982. An Evolutionary Theory of Economic Change. The Belknap Press of Harvard University Press, Cambridge.

Palley, T., 1994. Debt, aggregate demand, and the business cycle: an analysis in the spirit of Kaldor and Minsky. Journal of Post Keynesian Economics 163, 371-390.

Patriarca, F., Vona, F. Structural change and income distribution: an inverted-U relationship. Journal of Economic Dynamics and Control, in this issue.

Raberto, M., Teglio, A., Cincotti, S., 2012. Debt deleveraging and business cycles. An agent-based perspective. Economics: The Open-Access OpenAssessment E: Journal 6 (27).

Rosser, B.J., 2011. Complex Evolutionary Dynamics in Urban-Regional and Ecologic-Economic Systems: From Catastrophe to Chaos and Beyond. Springer, New York.

Rotemberg, J., 2008. Behavioral Aspects of Price Setting, and Their Policy Implications. Working Paper 13754. NBER.

Russo, A., Catalano, M., Gallegati, M., Gaffeo, E., Napoletano, M., 2007. Industrial dynamics, fiscal policy and RD: evidence from a computational experiment. Journal of Economic Behavior and Organization 64, 426-447.

Saviotti, P., Pyka, A., 2008. Product variety, competition and economic growth. Journal of Evolutionary Economics $18,323-347$.

Smets, F., Wouters, R., 2007. Shocks and frictions in US business cycles: a Bayesian DSGE approach. American Economic Review 97, 586-606.

Solow, R.M., 2008. The state of macroeconomics. Journal of Economic Perspectives 22, 243-246.

Stiglitz, J., 2011. Rethinking macroeconomics: what failed, and how to repair it. Journal of the European Economic Association 9, 591-645.

Stiglitz, J., Weiss, A., 1992. Credit rationing in markets with imperfect information. American Economic Review 71, $393-410$.

Stock, J., Watson, M., 1999. Business cycle fluctuations in US macroeconomic time series. In: Taylor, J., Woodford, M. (Eds.), Handbook of Macroeconomics, Elsevier Science, Amsterdam.

Taylor, L., O'Connell, S., 1985. A Minsky crisis. The Quarterly Journal of Economics 100, 871-885.

Tesfatsion, L., Judd, K. (Eds.), 2006. Handbook of Computational Economics II: Agent-Based Computational Economics, North Holland, Amsterdam.

Verspagen, B., 2002. Evolutionary macroeconomics: a synthesis between Neo-Schumpeterian and post-Keynesian lines of thought. The Electronic Journal of Evolutionary Modeling and Economic Dynamics 1007.

Woodford, M., 2003. Interest and Prices: Foundations of a Theory of Monetary Policy. Princeton University Press, Princeton, NJ. 